\title{
The interaction of fiscal and monetary policy in a monetary union: balancing credibility and flexibility
}

Citation for published version (APA):

Beetsma, R., \& Bovenberg, A. L. (1996). The interaction of fiscal and monetary policy in a monetary union: balancing credibility and flexibility. METEOR, Maastricht University School of Business and Economics. METEOR Research Memorandum No. 006 https://doi.org/10.26481/umamet.1996006

Document status and date:

Published: 01/01/1996

DOI:

10.26481/umamet.1996006

Document Version:

Publisher's PDF, also known as Version of record

\section{Please check the document version of this publication:}

- A submitted manuscript is the version of the article upon submission and before peer-review. There can be important differences between the submitted version and the official published version of record.

People interested in the research are advised to contact the author for the final version of the publication, or visit the DOI to the publisher's website.

- The final author version and the galley proof are versions of the publication after peer review.

- The final published version features the final layout of the paper including the volume, issue and page numbers.

Link to publication

\footnotetext{
General rights rights.

- You may freely distribute the URL identifying the publication in the public portal. please follow below link for the End User Agreement:

www.umlib.nl/taverne-license

Take down policy

If you believe that this document breaches copyright please contact us at:

repository@maastrichtuniversity.nl

providing details and we will investigate your claim.
}

Copyright and moral rights for the publications made accessible in the public portal are retained by the authors and/or other copyright owners and it is a condition of accessing publications that users recognise and abide by the legal requirements associated with these

- Users may download and print one copy of any publication from the public portal for the purpose of private study or research.

- You may not further distribute the material or use it for any profit-making activity or commercial gain

If the publication is distributed under the terms of Article $25 \mathrm{fa}$ of the Dutch Copyright Act, indicated by the "Taverne" license above, 


\title{
The Interaction of Fiscal and Monetary Policy in a Monetary Union: Balancing Credibility and Flexibility
}

\author{
Roel M.W.J. Beetsma \\ LIFE, University of Limburg, and CEPR \\ A. Lans Bovenberg \\ Central Planning Bureau and CEPR
}

\begin{abstract}
:
This paper explores how decentralized, national fiscal policies interact with a common monetary policy in a monetary union. We show that fiscal policy plays a more important role in stabilizing country-specific shocks than with national monetary policies. Whereas monetary unification with an optimally designed central bank reduces both expected inflation and the variance of inflation, it harms overall welfare by reducing output and public spending and increasing the variability of these variables. However, international transfers may avoid this decline in welfare.
\end{abstract}

Keywords: monetary union, stabilization, central bank conservatism, credibility, flexibility. JEL codes: $\quad$ E52, E58, E61, E62.

November 1995

Mailing address:

Roel Beetsma

LIFE/Department of Economics

University of Limburg

P.O.Box 616

6200 MD Maastricht

The Netherlands

* Part of this paper was written while Beetsma was a postdoctoral fellow at DELTA (Joint Research Unit CNRS-EHESS-ENS). He thanks DELTA for the stimulating research environment. 


\section{Introduction}

The plans for a European Monetary Union (EMU) have motivated a growing body of research on the optimal design of the common central bank. Much of this literature draws on the seminal work of Rogoff (1985) who showed that an optimally designed central bank involves a trade-off between credibility and flexibility. Extending this type of analysis to a monetary union, Laskar (1989) investigates how the optimal degree of conservatism of the central bank depends on the relative importance of common and idiosyncratic shocks. Alesina and Grilli (1992) focus on the degree of political independence of a European Central Bank (ECB) and the voting rules for the appointment of the ECB board members. Also Von Hagen and Süppel (1994) explore how the members of the central bank's council should be appointed and selected.

In contrast to monetary policy, fiscal policy remains largely a national responsibility within the EMU. The analytical literature on European monetary unification has paid relatively little attention to the role of national fiscal policies and their interaction with the common monetary policy. ${ }^{1}$ In a closed economy setting with national monetary policymaking, the interaction between monetary and fiscal policy has been analyzed by Alesina and Tabellini (1987), Debelle (1993) and Debelle and Fischer (1994). This paper draws on this literature to investigate how national fiscal policies interact with the common monetary policy in a monetary union. In fact, in the tradition of Phelps (1973) and Alesina and Tabellini (1987), we explore the role of monetary policy from a public finance perspective. In particular, the Barro-Gordon model of nominal wage contracting employed by Rogoff (1985) to investigate the trade-off between credibility and flexibility is extended to a monetary union with decentralized fiscal policymaking. Within this framework with endogenous fiscal policy, adverse output shocks are stabilized not only through the traditional channel of inflation surprises (as in Barro and Gordon (1983), Rogoff (1985), and Laskar (1989)) but also through lower taxes financed by additional seigniorage revenues ${ }^{2}$ and lower public spending. In this way, stabilization policy involves not only monetary but also fiscal policy. We find, in contrast to Rogoff (1985), that an optimally designed central bank, which ignores the social role of seigniorage, may be less conservative than society.

We show that, compared to the case with national monetary policymaking, stabilization policy in the EMU relies more on fiscal policy because country-specific shocks cannot be stabilized by the common monetary policy. The reduced stabilization role of monetary policy in a monetary union implies that, compared to the case with national monetary policies, the optimally designed central bank is more conservative in that it attaches a higher priority to price stability. Whereas

\footnotetext{
${ }^{1}$ Levine and Pearlman (1992) and Levine (1993) perform a numerical analysis of the interaction between fiscal and monetary policies in the EMU. Bryson, Jensen and Van Hoose (1993) and Bryson (1994) study monetary and fiscal coordination in a model of two interdependent economies which produce imperfectly substitutable goods. To keep the analysis of the trade-off between credibility and flexibility tractable, we will assume perfectly substitutable goods.

2 Calvo and and Guidotti (1993) also highlight the role of seigniorage revenues in macroeconomic stabilization for a variety of shocks in a model with monetary policy pre-commitment.
} 
monetary unification thus reduces both expected inflation and the variance of inflation, it harms overall welfare by reducing average output and public spending and increasing the variability of these variables. However, a properly designed system of international transfers may avoid this decline in welfare. In fact, countries would like to enter an economic and monetary union if this union involves international transfers stabilizing country-specific shocks. Intuitively, compared to national monetary and fiscal policies, international transfers are a more effectieve device to insure countries against adverse shocks. ${ }^{3}$

The remainder of the paper is organized as follows. Section 2 presents the model. Section 3 assumes that not only fiscal but also monetary policy is set at the national level. Both dependent and independent national central banks are considered. The case with national monetary policymaking explored in Section 3 serves as a benchmark for the analysis in Section 4, which is the heart of the paper. This section investigates the interaction between a union-wide monetary policy set by the common central bank (CCB) and decentralized fiscal policies set by the member states of the EMU. The analyses in Sections 3 and 4 are conducted in three steps. First, we study the macroeconomic effects on the level and variability of inflation, output, and public spending. Second, the welfare impacts are explored. Finally, we analyze the optimal design of the monetary institutions. Section 5 allows international transfers to stabilize country-specific shocks. Section 6 concludes.

\section{The model}

We will consider a monetary union which consists of $\mathrm{n}$ participating countries. Whereas labour is immobile internationally, there is a single commodity which is perfectly substitutable and perfectly tradable. Accordingly, the price level is uniform across the union. The private sectors and the fiscal authorities of the participating countries and the common central bank (CCB) of the union are involved in a game. The assumptions about the timing are as follows. First, nominal wages are concluded. Second, output shocks (see below) occur. Third, policy decisions are implemented. Finally, firms set output and employment.

Following, among others, Alesina and Tabellini (1987), Debelle (1993), Debelle and Fischer (1994) and Jensen (1994), we assume that workers in each country are represented by trade unions whose sole objective is to achieve a target expected real wage rate, the logarithm of which we normalize to zero. Therefore, the $(\log )$ of the nominal wage rate is set equal to the expected $(\log )$ price level, E(p). Expectations are rational. Hence, the subjective price expectation of wage

\footnotetext{
${ }^{3}$ Morales and Padilla (1995) study the role of a supranational transfer system in attaining the Pareto efficient cooperative outcome in a world composed of self-interested countries, whose monetary policies yield international spill-overs.
} 
setters, $p^{e}$, equals the mathematical expectation which follows from the model, i.e. $p^{e}=E(p){ }^{4}$

Output of a representative firm in country $i(i=1, . ., n)$ is given by:

$$
\mathrm{Y}_{\mathrm{i}}=\mathrm{L}_{\mathrm{i}}{ }^{\eta} \exp \left(\xi+\chi_{\mathrm{i}}\right), 0<\eta<1
$$

where $\mathrm{L}_{\mathrm{i}}$ is labor, $\xi$ represents a common shock hitting the entire union and ${ }_{\mathrm{i}} \chi$ is an identically distributed idiosyncratic shock hitting the economy of country $\mathrm{i}$ only. We assume that $\mathrm{E}(\xi)=0$, $\mathrm{E}\left(\chi_{\mathrm{i}}\right)=0 \forall \mathrm{i}, \mathrm{E}\left(\xi_{\chi}\right)=0 \forall \mathrm{i}$, and $\mathrm{E}(\chi \chi)=0 \forall \mathrm{i}, \mathrm{j}$ such that $\mathrm{i} \neq \mathbf{j}$. Moreover, we dęfine $\sigma^{2} \equiv \mathrm{E}\left(\xi^{2}\right)$ and $\sigma_{\chi \mathrm{i}}^{2} \equiv \mathrm{E}\left(\chi_{\mathrm{i}}^{2}\right)$.

Output in country $i$ is taxed at a rate $\tau_{i}$. The firm maximizes profits $\left(1_{i} \tau\right) P_{i} L{ }^{\eta} \exp \left(\xi+{ }_{i} \chi\right)-$ $\mathrm{WL}_{\mathrm{i}}$, where $\mathrm{P}$ and $\mathrm{W}$ represent, respectively, the price level and the wage rate (which are uniform across the entire union). Hence, $(\log )$ output is given by $y_{i}=(\eta /(1-\eta))\left(\pi-\pi^{e}-\tau_{i}+\log \eta\right)+\left(\xi+\chi_{j}\right) /(1-\eta)$, where $\pi$ denotes the inflation rate, $\pi^{e}$ represents the expected (by wage setters) inflation rate and $\log \left(1-\tau_{\mathrm{i}}\right)$ has been approximated by $-\tau$. For convenience, we normalize output by subtracting the constant $(\eta /(1-\eta)) \log \eta$ from $\mathrm{y}_{\mathrm{i}}$. Moreover, we redefine the common and idiosyncratic shocks by $\mu \equiv \xi /(1-\eta)$ and $\omega_{\mathrm{i}} \equiv \chi_{\mathrm{i}} /(1-\eta)$, respectively. ${ }^{5}$ Normalized output, $\mathrm{x}_{\mathrm{i}}$, thus amounts to

$$
x_{i}=v\left(\pi-\pi^{e}-\tau_{\mathrm{i}}\right)+\mu+\omega_{\mathrm{i}}, \text { where } \nu \equiv \eta /(1-\eta)>0 .
$$

A favorable supply shock $\mu+\omega_{\mathrm{i}}>0$ raises the marginal productivity of labor, thereby inducing firms to hire more labour. Thus, output increases on account of not only the direct effect of the positive supply shock but also the expansion of employment.

In the absence of tax distortions and stochastic shocks, $x_{i}=0$ in a rational expectations equilibrium (where $\pi=\pi^{\mathrm{e}}$ and $\mu=\omega_{\mathrm{i}}=0$, see (2.2)). In addition to distortionary output taxes, we allow for other, non-tax, distortions due to, for example, union power in the labor market or monopoly power in commodity markets. The first-best output level, i.e. output with neither tax nor non-tax distortions, is denoted by $\tilde{x}_{i}$. Thus, $\tilde{x}_{i}>0$ measures the non-tax distortions and can be interpreted as an implicit tax on output.

Society i's welfare loss function differs from that of the trade unions, because it accounts for the preferences of not only workers but also non-workers. Society i's preferences, which are defined over inflation, output and public spending, are represented by the following loss function:

$$
\mathrm{V}_{\mathrm{S}, \mathrm{i}}=1 / 2\left[\alpha_{\pi \mathrm{S}} \pi^{2}+\left(\mathrm{x}_{\mathrm{i}}-\tilde{\mathrm{x}}_{\mathrm{i}}\right)^{2}+\alpha_{\mathrm{gS}}\left(\mathrm{g}_{\mathrm{i}}-\tilde{\mathrm{g}}_{\mathrm{i}}\right)^{2}\right], \alpha_{\pi \mathrm{S}}, \alpha_{\mathrm{gS}}>0
$$

\footnotetext{
${ }^{4}$ Since wage contracts are signed before policies are selected, unions act as Stackelberg leaders vis-à-vis the authorities.

${ }^{5}$ From the definitions of $\mu$ and $\omega_{i}$, and the properties of $\xi$ and $\chi_{i}$, we have that $\mathrm{E}(\omega)=0 \forall \mathrm{i}, \mathrm{E}(\mu \omega)=0 \forall \mathrm{i}$, and $\mathrm{E}\left(\omega_{\mathrm{i}} \omega_{\mathrm{j}}\right)=0 \forall \mathbf{i}, \mathbf{j}$ such that $\mathbf{i} \neq \mathbf{j}$. Moreover, one has $\sigma_{\mu}{ }^{2} \equiv \mathrm{E}\left(\mu^{2}\right)=\sigma_{\tilde{\xi}}{ }^{2} /(1-\eta)^{2}$ and $\sigma_{\omega \mathrm{i}}{ }^{2} \equiv \mathrm{E}\left(\omega_{\mathrm{i}}{ }^{2}\right)=\sigma_{\chi \mathrm{i}}{ }^{2} /(1-\eta)^{2}$.
} 
Welfare losses increase in the deviations of inflation, $(\log )$ output and government spending $\left(\mathrm{g}_{\mathrm{i}}\right.$ is government spending as a share of non-distortionary output) from their targets. ${ }^{6}$ The target level of inflation corresponds to price stability while the target for output is given by its non-distortionary level, $\tilde{\mathbf{x}}_{\mathrm{i}}$. The target for government spending, $\tilde{\mathbf{g}}$, can be interpreted as the optimal share of nondistortionary output to be spent on public goods if sufficient lump-sum taxes are available (see Debelle and Fischer, 1994). Parameters $\alpha_{\pi \mathrm{S}}$ and $\alpha_{\mathrm{gS}}$ stand for the weights of the price stability and public spending objectives, respectively, relative to the weight of the output objective, which is normalized to unity. ${ }^{7}$ All countries feature the same relative preference weights. Targets for employment and public spending, in contrast, are allowed to vary across countries, reflecting different labor market institutions and preferences for public goods.

Each country features a fiscal authority or government. The loss function of the government of country i amounts to

$$
\mathrm{V}_{\mathrm{F}, \mathrm{i}}=1 / 2\left[\alpha_{\pi \mathrm{F}} \pi^{2}+\left(\mathrm{x}_{\mathrm{i}}-\tilde{\mathrm{x}}_{\mathrm{i}}\right)^{2}+\alpha_{\mathrm{gS}}\left(\mathrm{g}_{\mathrm{i}}-\tilde{\mathrm{g}}_{\mathrm{i}}\right)^{2}\right], \alpha_{\pi \mathrm{F}}>0
$$

We allow the governments' price stability weight, $\alpha_{\pi \mathrm{F}}$, to differ from society's price stability weight, $\alpha_{\pi \mathrm{S}}$, because, as shown by Rogoff (1985), society may be better off by appointing a policymaker whose preferences diverge from society's.

The government faces the following budget constraint ${ }^{8}$

$$
g_{i}+(1+\rho) d_{i}=\tau_{i}+\kappa \pi+\theta_{i}
$$

where $\rho$ denotes the (constant) real interest rate, $\mathrm{d}_{\mathrm{i}}>0$ represents the stock of single-period indexed government debt, and $\kappa \geq 0$ stands for the constant ratio of real money holdings ${ }^{9}$ (expressed as shares of output in the absence of distortions and stochastic shocks). Total seigniorage revenues collected by the CCB are equally distributed among the participants and are thus given by $\kappa \pi$ for an individual country. The government can employ only a limited, exogenous amount of lump-sum taxation, which as a share of output in absence of distortions and shocks equals $\theta_{\mathrm{i}}$.

We can rewrite the government budget constraint (2.5) as follows (by using (2.2)):

\footnotetext{
${ }^{6}$ Employment and output are directly related through the production function. Hence, instead of output, employment could have been included in the objective functions, with the target employment level corresponding to the employment level in absence of any distortions.

${ }^{7}$ In the limiting case of $\alpha_{g \mathrm{~S}} \rightarrow \infty$, the government spending share is set exogenously at $\tilde{\mathrm{g}}_{\mathrm{i}}$.

${ }^{8}$ For a derivation, see Appendix A in Beetsma and Bovenberg (1995a).

9 Alesina and Tabellini (1987), Debelle (1993), Debelle and Fischer (1994) and Jensen (1994), among others, assume that $\kappa=1$. However, as will become clear below, a non-unitary value of $\kappa$ plays an important role in our analysis.
} 


$$
\mathrm{GFR}_{\mathrm{i}} \equiv \mathrm{K}_{\mathrm{i}}-\left(\mu+\omega_{\mathrm{i}}\right) / \nu=\left[\left(\tilde{\mathrm{x}}_{\mathrm{i}}-\mathrm{x}_{\mathrm{i}}\right) / \nu\right]+\kappa \pi+\left[\tilde{\mathrm{g}}_{\mathrm{i}}-\mathrm{g}_{\mathrm{i}}\right]+\left[\pi-\pi^{\mathrm{e}}\right]
$$

where

$$
\mathrm{K}_{\mathrm{i}} \equiv \tilde{\mathrm{g}}_{\mathrm{i}}+(1+\rho) \mathrm{d}_{\mathrm{i}}+\tilde{\mathrm{x}}_{\mathrm{i}} / v-\theta_{\mathrm{i}}
$$

The government financing requirement, $\mathrm{GFR}_{\mathrm{i}}$, consists of a deterministic component, $\mathrm{K}$, and a stochastic component, $-\left(\mu+\omega_{i}\right) / v^{10}$ The deterministic component amounts to the government spending target $\tilde{\mathrm{g}}_{\mathrm{i}}$, debt servicing costs, $(1+\rho) \mathrm{d}_{\mathrm{i}}$, and a labor subsidy aimed at offsetting the implicit tax on output, $\tilde{x}_{i} / v$, net of the maximum amount of lump-sum taxes. The last right-hand side of (2.6) represents the four sources of finance. The first three terms correspond to the three components of the loss function, indicating that financing the government financing requirement is costly in terms of society's welfare. An inflation surprise is the fourth source of finance.

\section{National monetary policymaking}

In order to assess the effects of monetary unification, we first explore the benchmark of national monetary policymaking in some country $i(i=1, . ., n)$. As in Beetsma and Bovenberg (1995a), the first-best equilibrium (which yields zero welfare losses) is attained if a single benevolent policymaker, who sets both monetary and fiscal policy, can freely employ lump-sum taxation. If the use of lump-sum taxation is restricted (i.e. $\theta_{i}<\tilde{\mathbf{g}}+(1+\rho) \hat{\alpha}+\tilde{\mathrm{x}} / v$ ), the resulting equilibrium is second-best as long as the policymaker can commit to the optimal state-contingent rule. In this paper, however, we assume, rather realistically, that policymakers cannot commit. The absence of commitment gives rise to additional welfare losses.

\subsection{Centralized policymaking}

With centralized policymaking, the government of country i selects not only fiscal policy (taxation and public spending) but also monetary policy $\left(\pi_{\mathrm{i}}\right)$. This case can be interpreted as that of a dependent central bank. The equilibrium outcomes for $\kappa \pi_{i}, \tilde{g}_{-}-g$ and $(\tilde{\mathrm{x}}-\mathrm{x}) / v$ are contained in Table 1. ${ }^{11}$ Compared to the stochastic component, the deterministic component of the GFR exerts larger adverse impacts on price stability, output, and public spending. The reason for the relatively large negative impact of the deterministic component on the three determinants of welfare (i.e. inflation, output, and public spending) is that inflation surprises (i.e. the fourth source of finance at the right-hand side of (2.6)) contributes to the financing of only the stochastic component of the

${ }^{10}$ As will be shown below, the relative magnitudes of the deterministic and stochastic components of the government financing requirement are important factors in the optimal design of monetary institutions, which typically involves a trade-off between credibility and flexibility (see Rogoff (1985) and Cukierman (1992)).

${ }^{11}$ For a complete derivation of the solutions, see Appendix A. Note that the relevant expression for the government budget constraint is given by substituting $\pi_{i}$ for $\pi$ into (2.5). 
government financing requirement. Indeed, the coefficients of the deterministic component, $\mathrm{K}_{\mathrm{i}}$, in the expressions for $\kappa \pi_{\mathrm{i}}, \tilde{\mathrm{g}}_{\mathrm{i}}-\mathrm{g}_{\mathrm{i}}$ and $\left(\tilde{\mathrm{x}}_{\mathrm{i}}-\mathrm{x}_{\mathrm{i}}\right) / v$ sum to unity, while the corresponding coefficients of the stochastic component, $\left(\mu+\omega_{i}\right) / v$, sum to less than one. Only if the coefficient for the inflation surprise is added do these latter coefficients add up to unity, as required by the government financing requirement (2.6).

Inflation surprises cannot contribute to the financing of the deterministic component because wage setters feature rational expectations and thus anticipate the effect of the expected government financing requirement, $\mathrm{K}_{\mathrm{i}}$, on inflation when setting wages. Accordingly, a larger deterministic component raises inflation expectations. However, wage setters cannot anticipate the stochastic component of the government financing requirement because the stochastic shocks occur only after wage constracts have been signed. Accordingly, as far as the stochastic part of the government financing requirement is concerned, inflation expectations are exogenous. Inflation surprises, therefore, can contribute to the financing of the stochastic component.

An adverse output shock is stabilized through three channels (corresponding to the three non-output sources of financing at the last right-hand side of (2.6)): additional seigniorage, a cut in public spending raising the spending gap $\left(\tilde{\mathrm{g}}_{\mathrm{i}}-\mathrm{g}_{\mathrm{i}}\right)$, and an inflation surprise. The first and second channel allow for lower explicit taxes, while the third channel operates like an implicit output subsidy financed by employees. This latter channel has received scant attention in the literature. The first two channels, which involve fiscal policy, in contrast, have been largely ignored.

\section{Welfare}

Society i's equilibrium expected welfare loss amounts to (Appendix A)

$$
\mathrm{E}\left(\mathrm{V}_{\mathrm{S}, \mathrm{i}}\right)=\left(\frac{\alpha_{\pi \mathrm{S}}(\kappa+1)^{2} / \alpha_{\pi \mathrm{F}}^{2}+1 / v^{2}+1 / \alpha_{\mathrm{gS}}}{2 \mathrm{D}^{2}}\right) \tilde{\mathrm{K}}_{\mathrm{i}}^{2}+\left(\frac{\alpha_{\pi \mathrm{S}}(\kappa+1)^{2} / \alpha_{\pi \mathrm{F}}^{2}+1 / v^{2}+1 / \alpha_{\mathrm{gS}}}{2\left(\mathrm{D}^{*}\right)^{2}}\right)\left(\frac{\sigma_{\mu}^{2}+\sigma_{\omega \mathrm{i}}^{2}}{v^{2}}\right) \text {, }
$$

where $\mathrm{D} \equiv \kappa(\kappa+1) / \alpha_{\pi \mathrm{F}}+1 / v^{2}+1 / \alpha_{\mathrm{gs}}$ and $\mathrm{D} \equiv(\kappa+1) / \alpha \notin+1 \mathcal{\psi} \nu+1 / \alpha$. Society's welfare loss is thus composed of a term arising from the deterministic component of the government financing requirement and a term associated with the corresponding stochastic component. The coefficient in front of $\left(\sigma_{\mu}{ }^{2}+\sigma_{\omega i}{ }^{2}\right) / v^{2}$ is smaller than that in front of the deterministic component (because $\mathrm{D}>\mathrm{D}$ ). Intuitively, financing the stochastic component is least costly because it can in part be financed through inflation surprises as inflation expectations are not affected. The deterministic component, in contrast, is especially costly in terms of additional welfare losses because it raises inflation expectations as wage setters anticipate its inflationary consequences.

\section{Optimal institutions}

To find the optimal price stability weight of the policymaker, $\alpha_{\pi \mathrm{F}}$, we differentiate $\mathrm{E}\left(\mathrm{V}_{\mathrm{S}, \mathrm{i}}\right)$ with respect to $\alpha_{\pi \mathrm{F}}$, to yield: 


$$
\begin{gathered}
\partial \mathrm{E}\left(\mathrm{V}_{\mathrm{S}, \mathrm{i}}\right) / \partial \alpha_{\pi \mathrm{F}}=\left((\kappa+1) / \alpha_{\pi \mathrm{F}}{ }^{2}\right)\left(1 / \nu^{2}+1 / \alpha_{\mathrm{gS}}\right)\left[\mathrm{T}_{1} \mathrm{~K}_{\mathrm{i}}{ }^{2}+\mathrm{T}_{2}\left(\sigma_{\mu}{ }^{2}+\sigma_{\omega \mathrm{i}}{ }^{2}\right) / \nu^{2}\right] \\
\text { where } \mathrm{T}_{1} \equiv\left(\frac{\kappa-\alpha_{\pi \mathrm{S}}(\kappa+1) / \alpha_{\pi \mathrm{F}}}{\mathrm{D}^{3}}\right), \mathrm{T}_{2} \equiv\left(\frac{(\kappa+1)\left(1-\alpha_{\pi \mathrm{S}} / \alpha_{\pi \mathrm{F}}\right)}{\left(\mathrm{D}^{*}\right)^{3}}\right)
\end{gathered}
$$

In the absence of stochastic shocks, the welfare loss is minimised if $\alpha_{\pi \mathrm{F}}=(\kappa+1) \alpha_{\pi \mathrm{S}} / \kappa$. The government thus should be more conservative than society in the sense that it attaches a higher priority to price stability (i.e. $\alpha_{\pi \mathrm{F}}>\alpha_{\pi \mathrm{S}}$ ). This is a typical second best result: introducing a distortion (i.e. letting the preferences of the authorities diverge from those of society) in an already distorted world (due to the absence of commitment) may improve welfare. In the absence of commitment, the government takes inflation expectations as given and thus ignores the impact of its policy decisions on the inflation expectations of wage setters. An upward adjustment of the price stability weight induces the government to internalize the additional social costs of expansionary monetary policies in terms of higher inflation expectations.

The result that a conservative policymaker helps to offset welfare losses due to the absence of commitment was first noted by Rogoff (1985) in a model without fiscal policy. ${ }^{12}$ In Rogoff's model, anticipated inflation does not play any useful social role because seigniorage is absent (i.e. $\kappa=0$ ). Accordingly, minimization of the credibility component of the welfare loss would require an ultraconservative central banker (i.e. $\alpha_{\pi \mathrm{F}}$ would be infinite). In our model, in contrast, a finite price stability is optimal, even from the point of view of minimizing the deterministic losses (as long as money holdings are positive, i.e. $\kappa>0$ ).

In the other extreme case that the deterministic part of the government financing requirement is zero, the welfare loss is minimized if $\alpha_{\pi \mathrm{F}}=\alpha_{\pi \mathrm{S}}$. If the government financing requirement consists only of stochastic shocks, the policymaker does not face any commitment problems as inflation expectations are exogenously given. Accordingly, preferences do not need to be distorted to internalize the endogenous impact of discretionary policies on inflation expectations.

In the presence of both credibility problems (i.e. $K_{i}>0$ ) and stochastic shocks (i.e. $\left.\sigma_{\mu}^{2}+\sigma_{\omega i}^{2}>0\right)$, the optimal value of $\alpha$, denoted by $^{2} \alpha$, lies between $\alpha$ and $\left(k^{3}+1\right) \alpha / \kappa$. Accordingly, the optimally designed policymaker is more conservative than society. At $\alpha_{\pi \mathrm{F}}{ }^{\mathrm{opt}}, \mathrm{T}_{1}<0$ and $\mathrm{T}_{2}>0$. Hence, making the optimally designed central bank a bit more conservative yields firstorder welfare losses from the point of view of stabilizing stochastic shocks but first-order welfare gains from the point of view of gaining credibility in terms of lower inflation expectations. The optimal central bank is thus too conservative from the point of view of stabilizing the stochastic shocks (i.e. flexibility) but not conservative enough from the point of view of gaining credibility. Therefore, society faces a trade-off between flexibility (or stabilization) and credibility or, in terms

${ }^{12}$ In Rogoff's (1985) model the optimal degree of central bank conservatism depends only on supply shocks and not on the other shocks included in his model.

13 For $\alpha_{\pi \mathrm{F}} \leq \alpha_{\pi \mathrm{S}}, \mathrm{T}_{1}<0$ and $\mathrm{T} \leq 0$, hence $\partial \mathrm{E}(\mathrm{V}, \mathrm{Y}) / \mathrm{c}_{\mathrm{N}} \alpha<0$. For $\mathrm{F}_{\mathrm{F}} \alpha \geq\left(\kappa+1 d \alpha / \kappa_{\mathrm{g}}, \mathrm{T} \geq 0\right.$ and $\mathrm{T}>0$, hence $\partial \mathrm{E}\left(\mathrm{V}_{\mathrm{S}, \mathrm{i}}\right) / \partial \alpha_{\pi \mathrm{F}}>0$. Hence, the value of $\alpha_{\pi \mathrm{F}}$ which minimizes $\mathrm{E}\left(\mathrm{V}_{\mathrm{S}, \mathrm{j}}\right)$ lies between $\alpha_{\pi \mathrm{S}}$ and $(\kappa+1) \alpha_{\pi} \mathrm{d} / \mathrm{k}$. 
of the fiscal terminology of this paper, between optimally financing the unanticipated (i.e. stochastic) and the anticipated (i.e. deterministic) component of the government financing requirement.

The optimal price stability weight depends on the relative magnitudes of the two components of the government financing requirement. The larger the stochastic component becomes relative to the deterministic component (as indicated by a larger ratio $\left.\left(\sigma_{\mu}{ }^{2}+\sigma_{\omega}{ }\right) / \mathrm{K}_{\mathrm{i}}\right)^{2}$, the more important is flexibility compared to credibility and thus the lower becomes the optimal price stability weight. ${ }^{14}$

\subsection{Decentralized policymaking}

With decentralized policymaking, an independent central bank sets discretionary monetary policy, while fiscal policy continues to be determined by the government. The central bank and the government play a Nash game. Hence, both policymakers determine their policies simultaneously, taking each other's policies as given.

The central bank's loss function is given by

$$
\mathrm{V}_{\mathrm{M}, \mathrm{i}}=1 / 2\left[\alpha_{\pi \mathrm{M}} \pi_{\mathrm{i}}^{2}+\left(\mathrm{x}_{\mathrm{i}}-\tilde{\mathrm{x}}_{\mathrm{i}}\right)^{2}+\alpha_{\mathrm{gM}}\left(\mathrm{g}_{\mathrm{i}}-\tilde{\mathrm{g}}_{\mathrm{i}}\right)^{2}\right], \alpha_{\pi \mathrm{M}}>0, \alpha_{\mathrm{gM}} \geq 0 .{ }^{15}
$$

This yields the following reaction function (see Appendix B):

$$
\pi_{\mathrm{i}}=\left(\frac{v^{2}}{\alpha_{\pi \mathrm{M}}+v^{2}}\right)\left(\pi_{\mathrm{i}}^{\mathrm{e}}+\tau_{\mathrm{i}}+\left(\frac{\tilde{\mathrm{x}}_{\mathrm{i}}-\left(\mu+\omega_{\mathrm{i}}\right)}{v}\right)\right) .
$$

Larger (tax and non-tax) distortions in output and labor markets and higher expected inflation cause the monetary authority to raise inflation in order to protect employment. Adverse supply shocks act like implicit taxes on output and thus induce the CCB to offset these "taxes" through unanticipated inflation.

\section{Macroeconomic effects}

As in the case of centralization, inflation surprises contribute to the financing of only the stochastic component of the $\mathrm{GFR}_{\mathrm{i}}$. Hence, the coefficients of the deterministic component in the equilibrium outcomes for $\kappa \pi_{\mathrm{i}}$, $\tilde{\mathrm{g}}-\mathrm{g}$ and $\left(\tilde{\mathrm{x}}_{\mathrm{i}} \mathrm{x}\right) / \nu$ add up to one, while the coefficients of the

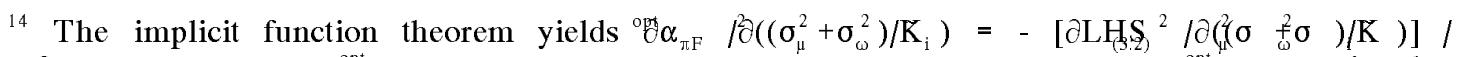
$\left[\partial \operatorname{LHS}_{(3,2)} / \partial \alpha_{\pi \mathrm{F}}\right]$, where $\alpha_{\pi \mathrm{F}}=\alpha_{\pi \mathrm{F}}{ }^{\mathrm{opt}}$. The conditions for an internal minimum of $\left.\mathrm{F}_{\mathrm{s}, \mathrm{V}} \mathrm{V}\right)$ a $\mathrm{a}_{\mathrm{F}}^{\mathrm{op} \alpha}$ require that

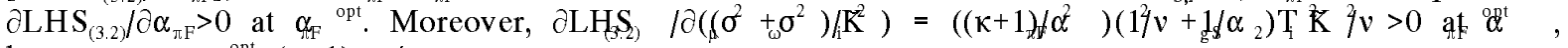
because $\alpha_{\pi S}<\alpha_{\pi \mathrm{F}}{ }^{\text {opt }}<(\kappa+1) \alpha_{\pi S} / \kappa$. zero.

${ }^{15}$ In fact, the public spending weight $\alpha_{\mathrm{gM}}$ is irrelevant for the outcomes, and could as well be set equal to 
stochastic part of $\mathrm{GFR}_{\mathrm{i}}$ sum to less than one (see Table 1). ${ }^{16}$

If the price stability weight of the central bank coincides with that of the government (i.e. $\alpha_{\pi \mathrm{M}}=\alpha_{\pi \mathrm{F}}$ ), the output gap (i.e $e_{1}(\tilde{\mathrm{x}}-\mathrm{x}) / v$ ) and the spending gap are on average larger under decentralization than under centralization. Seigniorage, in contrast, is on average smaller under decentralization. The reason is that an independent central bank fails to internalize the government budget constraint and thus ignores the role of seigniorage in financing the government financing requirement. The macroeconomic outcomes under centralization and decentralization coincide with each other only if real money holdings are zero so that seigniorage revenues are absent.

Table 2 presents the variances of inflation, public spending, and output. These variances indicate that decentralized policymaking implies that inflation is less variable (assuming $\alpha_{\pi \mathrm{M}}=\alpha_{\pi \mathrm{F}}$ ). Output is less successfully stabilized, although fiscal policy plays a more important role in stabilization policy as indicated by a higher variance of public spending.

\section{Welfare}

Society i's expected welfare loss amounts to (see Appendix B)

$$
\mathrm{E}\left(\mathrm{V}_{\mathrm{S}, \mathrm{i}}\right)=\left(\frac{\alpha_{\pi \mathrm{S}} / \alpha_{\pi \mathrm{M}}^{2}+1 / v^{2}+1 / \alpha_{\mathrm{gS}}}{2 \mathrm{~N}_{\mathrm{D}}^{2}}\right) \tilde{\mathrm{K}}_{\mathrm{i}}^{2}+\left(\frac{\alpha_{\pi \mathrm{S}} / \alpha_{\pi \mathrm{M}}^{2}+1 / v^{2}+1 / \alpha_{\mathrm{gS}}}{2\left(\mathrm{~N}_{\mathrm{D}}^{*}\right)^{2}}\right)\left(\frac{\sigma_{\mu}^{2}+\sigma_{\omega \mathrm{i}}^{2}}{v^{2}}\right),
$$

where $\mathrm{N}_{\mathrm{D}} \equiv \kappa / \alpha_{\pi \mathrm{M}}+1 / v^{2}+1 / \alpha_{\mathrm{gS}}$ and $\mathrm{N}_{\mathrm{b}}^{*} \equiv(\kappa+1) / \alpha_{\pi \mathrm{M}}+1 / \mathrm{v}^{2}+1 / \alpha_{\mathrm{gS}}$. As with centralized policymaking, the deterministic component of the government financing requirement is relatively costly because it raises inflation expectations and thus cannot be financed through inflation surprises. Consequently, the coefficient in front of the deterministic component (i.e. the term between brackets in the first term at the right-hand side of (3.5)) exceeds the coefficient in front of the variances of the shocks (i.e. the first factor in brackets in the second term at the right-hand side of (3.5)).

\section{The optimal central bank}

To find the optimal price stability weight of the independent central bank, we differentiate (3.5) with respect to $\alpha_{\pi \mathrm{M}}$ to obtain:

$$
\begin{gathered}
\partial \mathrm{E}\left(\mathrm{V}_{\mathrm{S}, \mathrm{i}}\right) / \partial \alpha_{\pi \mathrm{M}}=\left(1 / \alpha_{\pi \mathrm{M}}{ }^{2}\right)\left(1 / \nu^{2}+1 / \alpha_{\mathrm{gS}}\right)\left[\mathrm{T}_{3} \mathrm{~K}_{\mathrm{i}}^{2}+\mathrm{T}_{4}\left(\sigma_{\mu}^{2}+\sigma_{\omega \mathrm{ii}}{ }^{2}\right) / \nu^{2}\right], \\
\text { where } \mathrm{T}_{3} \equiv\left(\frac{\kappa-\alpha_{\pi \mathrm{S}} / \alpha_{\pi \mathrm{M}}}{\mathrm{N}_{\mathrm{D}}^{3}}\right), \mathrm{T}_{4} \equiv\left(\frac{(\kappa+1)-\alpha_{\pi \mathrm{S}} / \alpha_{\pi \mathrm{M}}}{\left(\mathrm{N}_{\mathrm{D}}^{*}\right)^{3}}\right) .
\end{gathered}
$$

The welfare loss arising from the deterministic component of the government financing requirement is minimized if $\alpha_{\pi \mathrm{M}}=\alpha_{\pi \mathrm{S}} / \kappa$. The welfare loss arising from the stochastic component of the

${ }^{16}$ Appendix B contains a derivation of the solutions. 
government financing requirement reaches its minimum for $\alpha_{\pi M}=\alpha_{\pi d} d(\kappa+1)$. The optimal price stability weight balances credibility and flexibility and thus lies between these two extremes $\alpha_{\pi S} /(\kappa+1)$ and $\alpha_{\pi S} / \kappa \cdot{ }^{17}$ Moreover, as in the case of centralized policymaking, the optimal price stability weight declines if stochastic shocks become relatively more important (as indicated by a larger ratio $\left.\left(\sigma_{\mu}^{2}+\sigma_{\omega i}^{2}\right) / K_{i}^{2}\right){ }^{18}$

With an independent central bank, the optimal price stability weights for minimizing the stochastic and deterministic components of the welfare losses are smaller than under centralized policymaking. The reason is that an independent central bank ignores the social value of seigniorage in relaxing the government financing requirement. A smaller price stability weight is an indirect instrument to have the independent central bank internalize this social value of inflation.

The social value of seigniorage causes our result to differ from that obtained by Rogoff (1985). He finds that the optimal central bank should always be more conservative than society. Intuitively, the only distortion in his model is the absence of commitment. In our model, in contrast, another distortion is present, namely the failure of the independent central bank to account for the social value of seigniorage. The optimal central bank is more conservative than society only if the distortions implied by the absence of commitment are large compared to the distortions due to the failure to internalize the social value of seigniorage. This is the case if, first, the deterministic component of the government financing requirement is large compared to the stochastic component and, second, real money holdings are small. The first condition ensures that commitment problems are relatively serious. The second condition implies that the social value of seigniorage is only small. Indeed, if money holdings are zero (i.e. $\kappa=0$ ), we reproduce Rogoff's result that the optimal central bank is unambiguously more conservative than society. Debelle (1993) and Debelle and Fischer (1994) assume that the money-output ratio is unity (i.e. $\kappa=1$ ). With these relatively large money holdings, the optimal central bank should be less conservative than society (unless stochastic shocks are absent). If $0<\kappa<1$, the central bank should be more conservative than society from the point of view of minimizing the deterministic loss (since $\kappa<1$ ) but less conservative than society from the point of view of minimizing the loss associated with the stochastic stocks (since $\mathrm{k}>0$ ). Accordingly, the optimal central bank may be more or less conservative than society depending on the relative importance of the stochastic versus the deterministic component of the government financing requirement.

\section{Monetary union}

${ }^{17}$ This can be seen from (3.6) by noting that $\mathrm{T}_{3}$ is negative (positive) if $x_{n \rightarrow}<(>) \& / \kappa$, while ${ }_{4} \mathrm{~T}$ is negative (positive) if $\alpha_{\pi \mathrm{M}}<(>) \alpha_{\pi \mathrm{s}} /(\mathrm{K}+1)$.

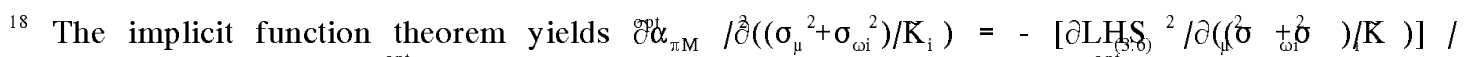

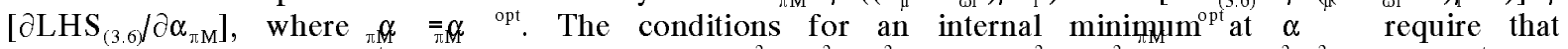

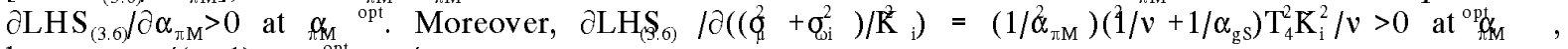
because $\alpha_{\pi \mathrm{s}} \mathrm{s}(\mathrm{K}+1)<\alpha_{\pi \mathrm{M}}^{\mathrm{opt}}<\alpha_{\pi \mathrm{s}} / \mathrm{K}$. 
In a monetary union, a common central bank (CCB) selects the inflation rate, which is uniform across the union. Fiscal policy continues to be selected at the national level. Policymakers continue to play Nash. Hence, they determine their policies simultaneously, taking as given each others' policies.

The CCB features the following welfare loss function:

$$
\mathrm{V}_{\mathrm{CCB}}=1 / 2\left\{\alpha_{\pi \mathrm{M}} \pi^{2}+\sum_{\mathrm{i}=1}^{\mathrm{n}}\left[\left(\mathrm{x}_{\mathrm{i}}-\tilde{\mathrm{x}}_{\mathrm{i}}\right)^{2}+\alpha_{\mathrm{gM}}\left(\mathrm{g}_{\mathrm{i}}-\tilde{\mathrm{g}}_{\mathrm{i}}\right)^{2}\right] / \mathrm{n}\right\}, \alpha_{\pi \mathrm{M}}>0, \alpha_{\mathrm{gM}} \geq 0,
$$

If $\alpha_{\pi \mathrm{M}}=\alpha_{\pi \mathrm{S}}$ and $\alpha_{\mathrm{gM}}=\alpha_{\mathrm{gS}}$, the objective function of the CCB is an equally weighted average of the individual societies' objective functions.

The CCB is not able to commit. It thus minimizes (4.1) subject to $(2.2), i=1, \ldots, n$, taking as given not only tax rates and public spending ratios but also expected inflation $\pi^{\mathrm{e}}$. The resulting reaction function amounts to (compare to (3.4)):

$$
\pi=\left(\frac{v^{2}}{\alpha_{\pi M}+v^{2}}\right)\left(\pi^{\mathrm{e}}+\frac{1}{\mathrm{n}} \sum_{\mathrm{i}=1}^{\mathrm{n}}\left(\tau_{\mathrm{i}}+\left(\frac{\tilde{\mathrm{x}}_{\mathrm{i}}-\left(\mu+\omega_{\mathrm{i}}\right)}{v}\right)\right)\right) .
$$

\section{Macroeconomic effects}

Table 1 contains the equilibrium outcomes. ${ }^{19}$ The expression for inflation is of the same general form as that under decentralized national policy making. However, in a monetary union, inflation cannot be attuned to country-specific circumstances. Instead, it is determined by union averages.

The expressions for the spending and output gaps are a bit more complicated. In interpreting these expressions, we distinguish between average and country-specific components of the government financing requirement. Monetary policy can finance only the average components $\mathrm{K}_{\mathrm{A}}$ and $\left(\mu+\omega_{\mathrm{A}}\right) / v$. Indeed, in a monetary union, policy responds in the same way to average variables as national policies do to country-specific variables with national monetary policymaking. Hence, the coefficients associated with the average components of the government financing requirement in the expressions for the spending and output gaps coincide with the corresponding coefficients under decentralized, national policymaking.

In a monetary union, monetary policy cannot contribute to financing the country-specific components $\left(\mathrm{K}_{A}-\mathrm{K}_{\mathrm{i}}\right)$ and $\left(\omega_{A}-\omega_{Y}\right) / v$. Indeed, $\left(\mathrm{K}_{\mathrm{A}}-\mathrm{K}_{\mathrm{Y}}\right)$ and $\left(\omega_{\mathrm{A}}-\omega_{\mathrm{l}}\right) / v$ do not feature in the expression for inflation. The loss of monetary policy as an instrument to finance country-specific components has implications for the level and variance of output and public spending. In particular, output is more sensitive to country-specific components than to average components. Accordingly, the coefficients in front of $\left(\mathrm{K}_{\mathrm{A}}-\mathrm{K}_{\mathrm{i}}\right)$ and $\left(\omega_{\mathrm{A}}-\omega_{\mathrm{i}}\right) / \nu$ in the expression for output exceed the corresponding coefficients in front of $\mathrm{K}_{\mathrm{A}}$ and $\left(\mu+\omega_{\mathrm{A}}\right) / \nu$. Moreover, the variance of output is larger in a monetary

\footnotetext{
19 These are derived in Appendix B.
} 
union because neither seigniorage nor inflation surprises can help to stabilize country-specific shocks (see Table 2).

Another implication of the loss of monetary policy to finance country-specific components is that fiscal policy has to bear the entire burden of financing these components. Indeed, public spending is more sensitive to the country-specific components of the government financing requirement than to the corresponding average component (see Table 1). The larger stabilization role of fiscal policy is reflected also in the larger variance of the public spending gap in a union (see Table 2).

We can use the results in Table 1 to order the sensitivity of the output and spending gaps with respect to the four components of the government financing requirement. In particular, the average stochastic component is stabilized best in the sense that it exerts the smallest impact on output and spending. The reason is that not only seigniorage but also inflation surprises contribute to the financing of this component. The average deterministic component is an intermediate case as far as its impact on output and spending is concerned. Union-wide monetary policy contributes to the financing of this component by generating seigniorage. ${ }^{20}$ However, with rational wage setters anticipating inflation, monetary policy cannot generate inflation surprises and is thus less effective in reducing the variations in output and spending than for the average stochastic component. The country-specific (stochastic and deterministic) components exert the largest impact on the output and spending gaps because monetary policy cannot play any role in financing these components (i.e. neither through seigniorage nor through inflation surprises).

\section{Welfare}

From now on, the deterministic components of the government financing requirements and the variances of the idiosyncratic shocks are assumed to be uniform across the union (i.e. $\mathrm{K}_{\mathrm{i}}=\mathrm{K}$ and $\sigma_{\omega i}^{2}=\sigma_{\omega}^{2}$ for all i). Under these assumptions, the equilibrium welfare loss amounts to (see Appendix B):

$$
\begin{gathered}
\mathrm{E}\left(\mathrm{V}_{\mathrm{S}, \mathrm{i}}\right) \equiv\left(\frac{\alpha_{\pi \mathrm{S}} / \alpha_{\pi \mathrm{M}}^{2}+1 / v^{2}+1 / \alpha_{\mathrm{gS}}}{2 \mathrm{~N}_{\mathrm{D}}^{2}}\right) \tilde{\mathrm{K}}^{2}+ \\
\left(\frac{\alpha_{\pi \mathrm{S}} / \alpha_{\pi \mathrm{M}}^{2}+1 / v^{2}+1 / \alpha_{\mathrm{gS}}}{2\left(\mathrm{~N}_{\mathrm{D}}^{*}\right)^{2}}\right)\left(\frac{\sigma_{\mu}^{2}}{v^{2}}\right)+\left(\frac{1}{2\left(1 / v^{2}+1 / \alpha_{\mathrm{gS}}\right)}\right)\left(\frac{\sigma_{\omega}^{2}}{v^{2}}\right)+
\end{gathered}
$$

\footnotetext{
${ }^{20}$ With very small money holdings (i.e. $\kappa=0$, which corresponds to the case of Rogoff, 1985), the average deterministic component exerts the same impact on output and spending as the country-specific components. However, even if $\kappa=0$, monetary policy continues to perform a useful role in stabilizing average stochastic shocks.
}

${ }^{21}$ If $\mathrm{n}=1,(4.3)$ reduces to $(3.5)$, the welfare loss under decentralized national monetary policymaking. 


$$
\left(\left(\frac{\alpha_{\pi \mathrm{S}} / \alpha_{\pi \mathrm{M}}^{2}+1 / v^{2}+1 / \alpha_{\mathrm{gS}}}{\left(\mathrm{N}_{\mathrm{D}}^{*}\right)^{2}}\right)-\left(\frac{1}{1 / v^{2}+1 / \alpha_{\mathrm{gS}}}\right)\right)\left(\frac{\sigma_{\mathrm{d}}^{2} / \mathrm{n}}{2 v^{2}}\right), \mathrm{i}=1, \ldots, \mathrm{n}
$$

If it leaves the preference weights unaffected, monetary unification (i.e. an increase in the number of countries $n)$ raises welfare if the coefficient of $\left(\sigma_{\omega}{ }^{2} / n\right) / 2 v^{2}$ in the last term at the right-hand side of (4.3) is positive. This condition can be reduced to

$$
\alpha_{\pi \mathrm{M}}<\left(\frac{\alpha_{\pi \mathrm{S}}}{2(\kappa+1)}\right)-\left(\frac{\kappa+1}{2\left(1 / v^{2}+1 / \alpha_{\mathrm{gS}}\right)}\right) .
$$

Thus, monetary unification enhances welfare only if the central bank is substantially less conservative than society. Intuitively, if condition (4.4) is met, inflation plays an excessive role in stabilizing output. Monetary unification acts as an indirect instrument to reduce the excessive stabilization because in a monetary union monetary policy can no longer be used as effectively to stabilize country-specific shocks $\left(\omega_{\mathrm{A}}-\omega_{\mathrm{i}}\right) / v$.

In practice, the central bank is not likely to be less conservative than society. For example, monetary unification unambiguously harms welfare if the price stability weight of the central bank coincides with the society's corresponding preference weight $\left(\alpha_{\pi \mathrm{M}}=\alpha_{\pi \mathrm{S}}\right)$. In this case, the central bank's price stability weight exceeds the optimal price stability weight from a stabilization point of view, $\alpha_{\pi \mathrm{s}} /(\kappa+1)$. Accordingly, by reducing the stabilization role of monetary policy, monetary unification moves the degree of stabilization even further from its optimum, thereby harming welfare. These adverse welfare effects of unification are avoided only if the idiosyncratic shocks would be absent (i.e. $\sigma_{\omega}^{2}=0$ ) so that not only the deterministic components but also the stochastic components of the government financing requirement would converge. ${ }^{22}$

Expression (4.3) indicates when the less effective use of monetary policy as an instrument to stabilize country-specific shocks in a monetary union is particularly serious. This is the case if, first, country-specific shocks are important (as indicated by large values for $\sigma_{\omega}{ }^{2}$ ), second, monetary policy is an effective instrument to stabilize output and, third, compared to monetary policy, fiscal policy is especially costly as an instrument of stabilization policy. The second condition is met if the short-run Phillipscurve is steep so that inflation surprises are an effective instrument to stabilize output. The third condition for monetary policy to be a valuable instrument of stabilization policy is met if a small price stability weight $\alpha_{\pi \mathrm{S}}$ indicates that fluctations in inflation are not costly while a large public spending weight $\alpha_{\mathrm{gS}}$ indicates that fluctuations in public spending are especially costly.

${ }^{22}$ If the idiosyncratic shocks are absent, the government financing requirements in all countries coincide. With perfect convergence of government financing requirements, monetary policy does not need to be attuned to country-specific circumstances. 


\section{The optimal common central bank}

The optimal price stability weight of the CCB is found by differentiating (4.3) with respect to its price stability weight:

$$
\partial \mathrm{E}\left(\mathrm{V}_{\mathrm{S}, \mathrm{i}}\right) / \partial \alpha_{\pi \mathrm{M}}=\left(1 / \alpha_{\pi \mathrm{M}}{ }^{2}\right)\left(1 / \nu^{2}+1 / \alpha_{\mathrm{gS}}\right)\left[\mathrm{T}_{3} \mathrm{~K}^{2}+\mathrm{T}_{4}\left(\sigma_{\mu}{ }^{2}+\sigma_{\omega}{ }^{2} / \mathrm{n}\right) / v^{2}\right], \mathrm{i}=1, \ldots, \mathrm{n},
$$

where $T_{3}$ and $T_{4}$ are as defined in (3.6). Just as with an independent national central bank, the optimal price stability weight lies between $\alpha_{\pi \mathrm{d}} /(\kappa+1)$ and $\alpha_{\mathrm{s}} / \kappa$. Monetary unification (i.e. an increase in the number of participants in the union, $n$ ) raises the optimal price stability weight by reducing the variance of the common shocks $\left(\sigma_{\mu}{ }^{2}+\sigma_{\omega}{ }^{2} / \mathrm{n}\right.$ ) and thus the ratio ${ }_{\mu}^{2} \sigma{ }_{\omega}^{+2} \sigma / \mathrm{n}$ )/K (see footnote 18). Moreover, if idiosyncratic shocks become more important relative to common shocks, ${ }^{23}$ union-wide monetary policy becomes less effective in stabilizing (or 'financing') the stochastic components of the government financing requirements. With monetary policy becoming a less effective stabilization tool, the union members should appoint a more conservative central banker so that monetary policy focusses more on credibility and less on flexibility. ${ }^{24}$

Enlarging a monetary union while optimally adjusting monetary arrangements not only promotes price stability by reducing the average level of inflation but also reduces the variability of inflation. However, the other components of welfare (i.e. output and public spending) suffer as monetary policy contributes less to the financing of the government financing requirement. Moreover, the variability of both output and spending increases as monetary policy provides less stabilization and fiscal policy takes over part of the stabilization task. ${ }^{25}$

The overall effect of these changes on the various components in welfare is that monetary unification with optimal adjustment of monetary institutions unambiguously reduces welfare. ${ }^{26}$ Intuitively, the optimally designed central bank, which trades off credibility and flexibility, does

\footnotetext{
${ }^{23}$ In this experiment, we raise the ratio $\sigma_{\omega}^{2} / \sigma_{\mu}^{2}$ while keeping constant the overall variance of the shocks, $\sigma_{\mu}^{2}+\sigma_{\omega}^{2}$.

24 This result is reminiscent of Laskar (1989) who analyses the optimal degree of central bank conservatism in open economies with imperfectly substitutable commodities and national monetary policies. $\mathrm{He}$ shows that the national central banks should be made more conservative if shocks become more idiosyncratic.
}

${ }^{25}$ The expressions for the variability of output and public spending in Table 2 are increasing in both $n$ and the price stability weight of the central bank. Accordingly, this variability increases for two reasons. First, with given preferences of the central bank, the central bank is less effective in stabilization if the union grows. Second, the union members find it optimal to raise the price stability weight of the central bank. This reduces the stabilization role of monetary policy further, thereby increasing the variability of output and spending.

${ }^{26}$ To see this more formally, write $E\left(V_{S, i}\right)$ as a function $V$ of $\alpha_{M}$ and $n$, and $l_{\pi} t_{\pi}{ }^{\text {opt }}$ (p) denote the optimal $\alpha_{\mathrm{TM}}$ for a union of size $\mathrm{p}$. Hence, by definition of $\alpha^{\mathrm{opt}_{\mathrm{m}}}(\mathrm{p})$ one has $\mathrm{M}_{\mathrm{M}}$ that $\mathrm{V}\left(\AA^{\mathrm{pt}}(\mathrm{m}), \mathrm{m}\right)<$ $\mathrm{V}\left(\alpha_{\pi \mathrm{M}}{ }^{\mathrm{opt}}(\mathrm{m}+1), \mathrm{m}\right)<\mathrm{V}\left(\alpha_{\pi \mathrm{M}}{ }^{\mathrm{opt}}(\mathrm{m}+1), \mathrm{m}+1\right)$, which is the welfare loss under an optimal union of size $\mathrm{m}+1$. The last inequality holds because the coefficient of $\left(\sigma_{\omega}{ }^{2} / \mathrm{n}\right) /\left(2 v^{2}\right)$ in $(4.3)$ is negative at $\alpha_{\pi \mathrm{M}}=\alpha_{\pi \mathrm{M}}{ }^{\mathrm{opt}}(\mathrm{m}+1)$ (which lies between $\alpha_{\pi M} /(\kappa+1)$ and $\left.\alpha_{\pi M} / \kappa\right)$. 
not provide enough stabilization. By further reducing stabilization, a larger union yields a firstorder welfare loss.

\section{International transfers}

This section studies the potential role of a supranational transfer system in insuring countries against country-specific shocks. Hence, not only monetary policy but also parts of fiscal policy are centralized. Transfer payments occur after shocks have realized but before policies are selected. The deterministic components of the government financing requirements and the variances of the idiosyncratic shocks are uniform across the union. ${ }^{27}$ In setting transfers, a supranational authority weighs all countries equally. Accordingly, optimal transfers $\left\{\mathrm{t}_{\mathrm{i}}\right\}_{\mathrm{i}=1}^{\mathrm{n}}$ minimize $(1 / \mathrm{n}) \sum_{\mathrm{i}=1}^{\mathrm{n}} \mathrm{V}_{\mathrm{S}, \mathrm{i}}$ subject to the condition that $\sum_{i=1}^{n} t_{i} \leq 0$ (i.e. feasibility) and the modified government financing requirements,

$$
\mathrm{K}-\left(\mu+\omega_{\mathrm{i}}\right) / \nu-\mathrm{t}_{\mathrm{i}}=\left[\left(\tilde{\mathrm{x}}_{\mathrm{i}}-\mathrm{x}_{\mathrm{i}}\right) / v\right]+\kappa \pi+\left[\tilde{\mathrm{g}}_{\mathrm{i}}-\mathrm{g}_{\mathrm{i}}\right]+\left[\pi-\pi^{\mathrm{e}}\right], \mathrm{i}=1, \ldots, \mathrm{n} .
$$

The quadratic welfare losses imply that optimal transfers equate ex post welfare losses across the union. Thus, the optimal combination of transfers amounts to

$$
t_{i}=\left(\omega_{A}-\omega_{i}\right) / v, i=1, . ., n .
$$

This implies that individual countries are perfectly insured against the country-specific shock components. The associated expected welfare loss is given by

$$
\mathrm{E}\left(\mathrm{V}_{\mathrm{S}, \mathrm{i}}\right)=\left(\frac{\alpha_{\pi \mathrm{S}} / \alpha_{\pi \mathrm{M}}^{2}+1 / v^{2}+\alpha_{\mathrm{gS}}^{-1}}{2 \mathrm{~N}_{\mathrm{D}}^{2}}\right) \tilde{\mathrm{K}}^{2}+\left(\frac{\alpha_{\pi \mathrm{S}} / \alpha_{\pi \mathrm{M}}^{2}+1 / v^{2}+\alpha_{\mathrm{gS}}^{-1}}{2\left(\mathrm{~N}_{\mathrm{D}}^{*}\right)^{2}}\right)\left(\frac{\sigma_{\mu}^{2}+\sigma_{\mathrm{\omega}}^{2} / \mathrm{n}}{v^{2}}\right), \mathrm{i}=1, \ldots, \mathrm{n} .
$$

With fixed preference weights (including a given $\alpha_{\pi M}$ ), a larger union raises welfare because it increases the potential to insure idiosyncratic shocks. Thus, whereas monetary unification without international transfers harms welfare, it raises welfare if it is accompanied by a properly designed transfer system. ${ }^{28}$

Just as in the absence of international transfers, the optimal central bank becomes more

${ }^{27}$ The assumption that $\mathrm{K}_{\mathrm{i}}=\mathrm{K}, \forall \mathrm{i}$, ensures that the optimal transfers only depend on country-specific shock components. Hence, transfers are used purely for insurance purposes and are zero from an ex ante point of view.

${ }^{28}$ This welfare gain is due to the international transfer system rather than monetary unification. With decentralized national monetary policymaking, the international transfer system would yield the same welfare gain. However, in the presence of such an optimally designed transfer system, transfering monetary policy to the central level of the union would not yield any welfare losses since international transfers rather than national monetary policy would stabilize country-specific shocks. 
conservative in a larger union. The reason is that a larger union implies more effective stabilization through international transfers. This reduces the role of monetary policy in stabilizing the economy. Hence, in trading off credibility and flexibility, the optimal central bank should focus more on credibility. In contrast to the case without international transfers, the variability of also output and spending is reduced because the enhanced stabilization performed by the transfers decreases output variability. Moreover, it reduces the need to employ national fiscal policies as a stabilization tool, thereby decreasing the variability of public spending.

The enhanced insurance through an international transfer system implies that a larger union with optimally designed monetary institutions and international transfers enhances welfare. Hence, just as with fixed monetary institutions, a larger union is welfare enhancing only if it involves international transfers.

\section{Conclusions}

In investigating the macroeconomic implications of monetary unification, this paper focussed on the links between fiscal and monetary policy in stabilizing and boosting employment. In the presence of endogenous fiscal policies, employment is stabilized not only through the traditional channel of inflation surprises but also through variations in seigniorage revenues and public spending. With national policymaking, we found that, in contrast to Rogoff (1985), the optimally designed central bank may be less conservative than society if real money holdings are large and supply shocks are important compared to the deterministic component of the government financing requirement (which is affected by spending targets, public debt service, lump-sum taxes, and non-tax distortions in output and labor markets).

In the absence of international transfers, monetary unification implies less effective stabilization of country-specific shocks. This raises the variability of not only output but also public spending as national fiscal policies bear more of the burden of stabilizing country-specific shocks. Unless national central banks attach a very low priority to price stability and thus focus too much on stabilization, less effective stabilization in a monetary union reduces overall welfare compared to national monetary policymaking.

We studied also the optimal design of monetary institutions. We found that, compared to the national central banks, the optimally designed common central bank should focus more on price stability because monetary policy becomes a less effective stabilization tool in a monetary union. This explains why European central bankers generally favor European monetary unification.

If monetary unification is accompanied by an optimally designed international transfer system, the implied insurance of country-specific shocks actually results in more effective rather than less effective stabilization, thereby reducing the variability of not only inflation but also output and spending. Accordingly, monetary unification raises welfare only if it is accompanied by a properly designed system of international transfers. This result suggests an important relationship 
between monetary and political integration because international transfers (i.e. centralizing not only monetary policy but also parts of fiscal policy) are likely to be feasible only in a union with sufficient political integration. ${ }^{29}$ In addition to political obstacles, another (and related) barrier to such a transfer system is that country-specific shocks may be difficult to observe. In particular, individual countries are likely to possess more information on these shocks than the surpanational transfer agency. This may give rise to moral hazard. These topics are left for future research. Another important direction for further research is to allow governments to run deficits or surpluses. Within such a framework, stabilization could occur not only through international transfers, monetary policy, or variations in public spending, but also through public debt policy. Thus, we could study the role of ceilings on public debt, which currently serve as entrance requirements for the EMU. These debt targets may imply benefits in terms of avoiding excessive accumulation of public debt in the presence of myopic policymakers (see Beetsma and Bovenberg, 1995b). However, they may impose also costs by reducing the ability of debt policy to stabilize country-specific shocks.

\section{References}

Alesina, A. and V.U. Grilli (1992), "The European Central Bank: Reshaping Monetary Politics in Europe', in Canzoneri, M.B., Grilli, V.U. and P. Masson, The Creation of a Central Bank, Cambridge University Press and CEPR.

Alesina, A. and G. Tabellini (1987), 'Rules and Discretion with Non-Coordinated Monetary and Fiscal Policies', Economic Inquiry, Vol.25, pp.619-30.

Barro, R.J. and D.B. Gordon (1983), 'Rules, Discretion and Reputation in a Model of Monetary Policy, Journal of Monetary Economics, Vol.12, pp.101-121.

Beetsma, R.M.W.J. and A.L. Bovenberg (1995a), 'Designing Fiscal and Monetary Institutions in a Second-Best World', CentER Discussion Paper, No.9547.

Beetsma, R.M.W.J. and A.L. Bovenberg (1995b), 'Does Monetary Unification Lead to Excessive Debt Accumulation?', Document, No.95-23, DELTA.

Bryson, J.H. (1994), 'Macroeconomic Stabilization Through Monetary and Fiscal Policy Coordination: Implications for European Monetary Union', Open Economies Review, Vol.5, pp.307-26.

Bryson, J.H., Jensen, H. and D.D. Van Hoose (1993), 'Rules, Discretion, and International Monetary and Fiscal Policy Coordination', Open Economies Review, Vol.4, pp.117-32.

Calvo, G.A. and P.E. Guidotti (1993), 'On the Flexibility of Monetary Policy: The Case of the Optimal Inflation Tax', Review of Economic Studies, Vol.60, pp.667-87.

Cukierman, A. (1992), Central Bank Strategy, Credibility, and Independence, MIT Press,

${ }^{29}$ In the United States, the federal fiscal system serves as a transfer system stabilizing region-specific shocks (see, e.g., Sala-i-Martin and Sachs, 1991). Europe, however, lacks such an insurance mechanism. 
Cambridge, Massachusetts.

Debelle, G. (1993), 'Central Bank Independence: A Free Lunch?', mimeo, MIT.

Debelle, G. and S. Fischer (1994), 'How Independent Should a Central Bank Be?', CEPR Publication, No.392.

Eijffinger, S.C.W. and E. Schaling (1995), "The Ultimate Determinants of Central Bank Independence', CentER Discussion Paper, No.9505.

Jensen, H. (1994), 'Loss of Monetary Discretion in a Simple Monetary Policy Game', Journal of Economic Dynamics and Control, Vol.18, pp.763-79.

Laskar, D. (1989), 'Conservative Central Bankers in a Two-Country World', European Economic Review, Vol.33, pp.1575-95.

Levine, P. (1993), 'Fiscal Policy Co-ordination under EMU and the Choice of Monetary Instrument', The Manchester School, Vol.41, pp.1-12, Supplement.

Levine, P. and J. Pearlman (1992), 'Fiscal and Monetary Policy under EMU: Credible Inflation Target or Unpleasant Monetarist Arithmetic?', CEPR Discussion Paper, No. 701.

Morales, A.J. and A.J. Padilla (1995), 'Designing Institutions for International Monetary Policy Cooperation', CEPR Discussion Paper, No.1180.

Phelps, E.S. (1973), 'Inflation in the Theory of Public Finance', Swedish Journal of Economics, Vol.75, pp.67-82.

Rogoff, K. (1985), 'The Optimal Degree of Commitment to an Intermediate Monetary Target', Quarterly Journal of Economics, Vol.99, pp.1169-89.

Sala-i-Martin, X. and Jeffrey Sachs (1991), 'Fiscal Federalism and Optimum Currency Areas: Evidence for Europe from the United States', NBER Working Paper, No.3855.

Von Hagen, J. and R. Süppel (1994), 'Central Bank Constitutions for Federal Monetary Unions', European Economic Review, Vol.38, pp.774-82. 
Table 1: Outcomes of the output gap and the policy instruments

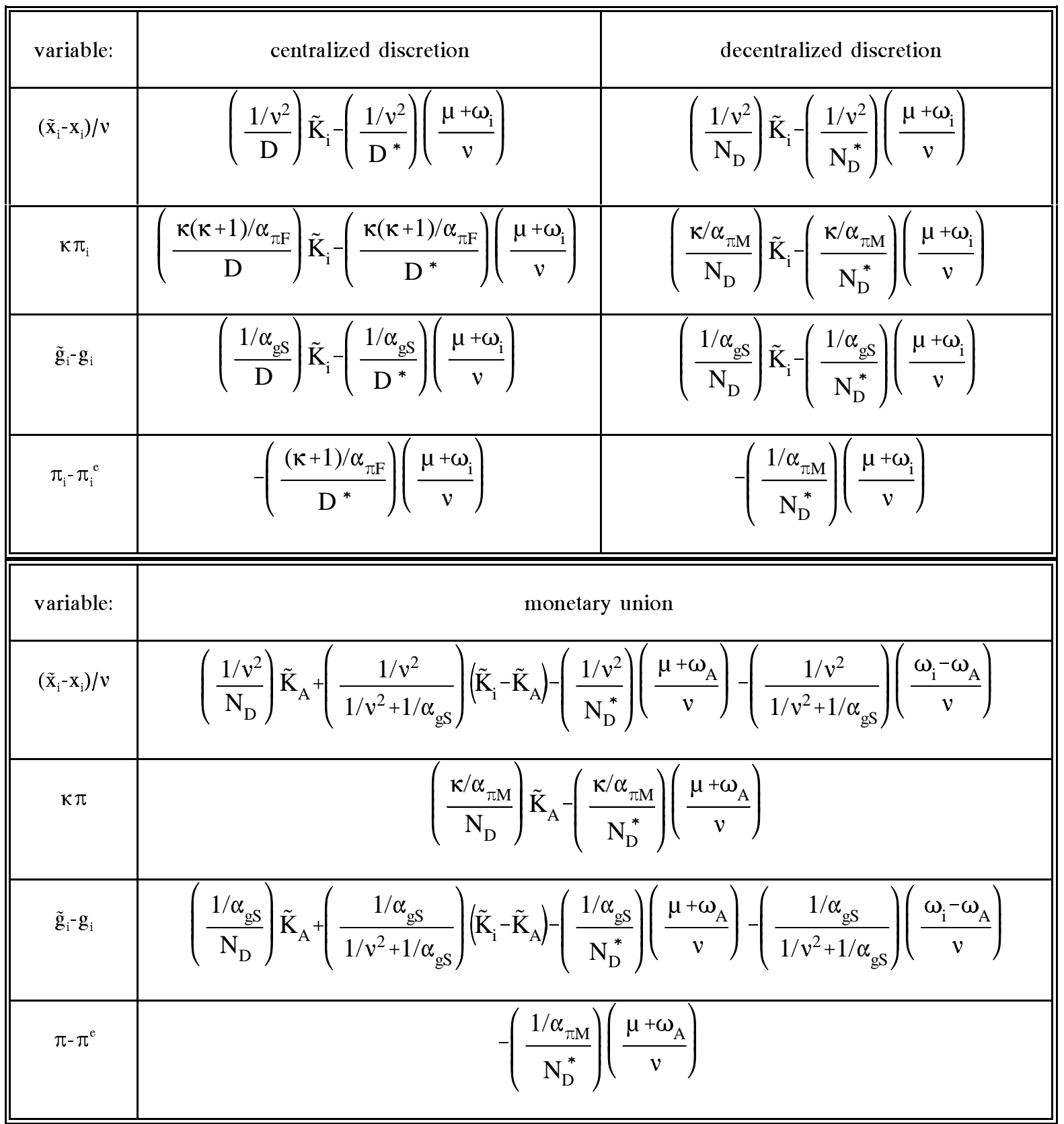

Note: $\quad \mathrm{D} \equiv \kappa(\kappa+1) / \alpha_{\pi \mathrm{F}}+1 / v^{2}+1 / \alpha_{\mathrm{gS}}>0, \quad * \quad \mathrm{D} \equiv\left(\kappa+\frac{1}{\mathrm{f}}\right)^{2} / \alpha+1 / \nu_{\mathrm{g}} \mathrm{S} 1 / \alpha^{2}>0, \quad{ }_{\pi \mathrm{M}} \mathrm{N} \equiv \kappa / \alpha \quad{ }_{\mathrm{g}} \mathrm{s} 1 / v^{2}+1 / \alpha>0 \quad$ and $\mathrm{N}_{\mathrm{D}}{ }^{*} \equiv(\kappa+1) / \alpha_{\pi \mathrm{M}}+1 / \nu^{2}+1 / \alpha_{\mathrm{gS}}>0$. 
Table 2: Variances of output and policy instruments

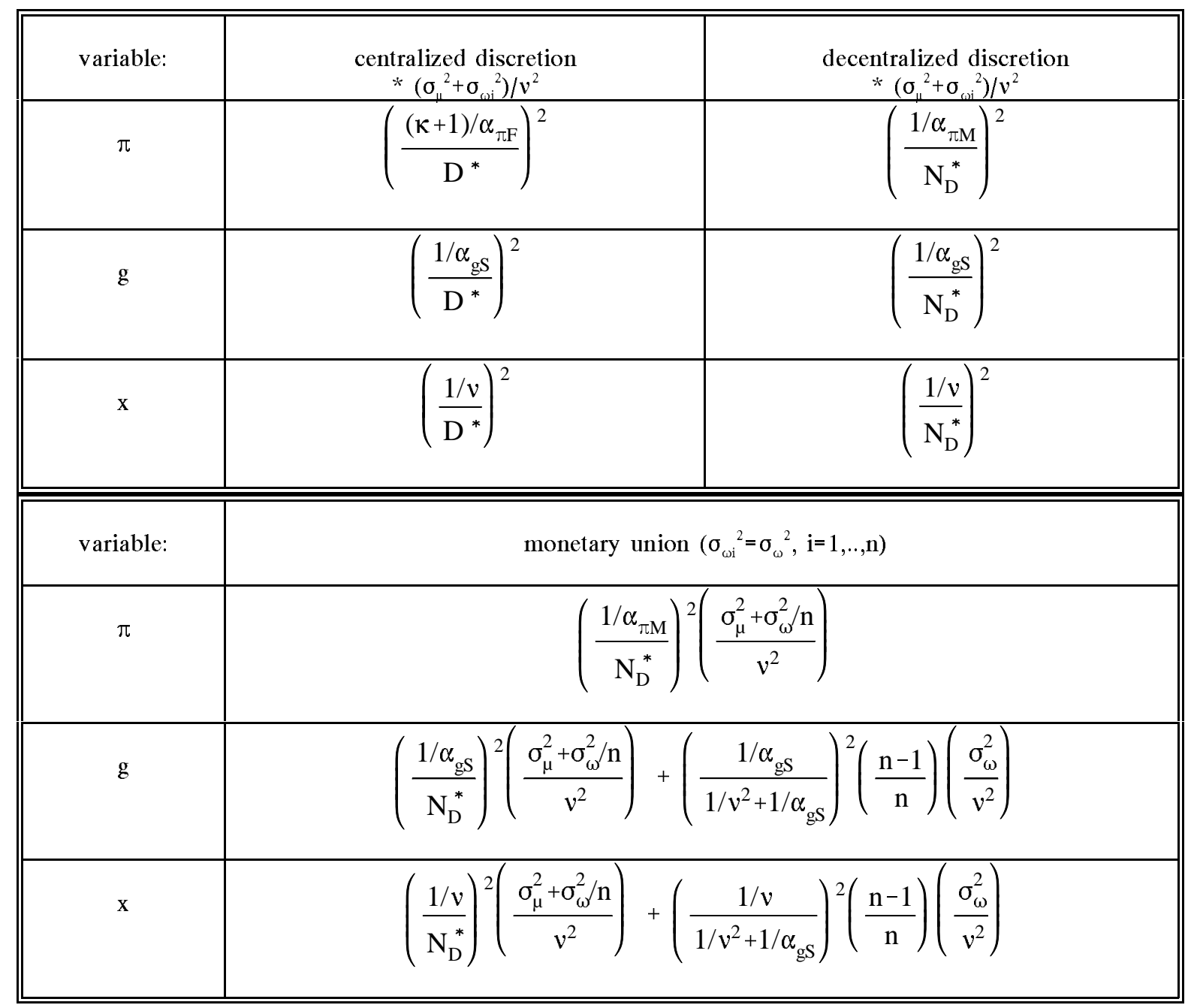

Definitions: See Table 1 


\section{Technical appendices:}

\section{A: Derivation of the outcomes under centralized discretion}

Substitute (2.2) for $x_{i}$ into (2.4). The Lagrangian of the government of country $i$ is:

$$
\mathfrak{f}_{\mathrm{F}, \mathrm{i}}=1 / 2\left[\alpha_{\pi \mathrm{F}} \pi_{\mathrm{i}}^{2}+\left(v\left(\pi_{\mathrm{i}}-\pi_{\mathrm{i}}^{\mathrm{e}}-\tau_{\mathrm{i}}\right)+\left(\mu+\omega_{\mathrm{i}}\right)-\tilde{\mathrm{x}}_{\mathrm{i}}\right)^{2}+\alpha_{\mathrm{gs}}\left(\mathrm{g}_{\mathrm{i}}-\tilde{\mathrm{g}}_{\mathrm{i}}\right)^{2}\right]+\lambda_{\mathrm{i}}\left[g_{\mathrm{i}}+(1+\rho) \mathrm{d}_{\mathrm{i}}-\tau_{\mathrm{i}}-\kappa \pi_{\mathrm{i}}-\theta_{\mathrm{i}}\right]
$$

The first order conditions for $\pi_{\mathrm{i}}, \tau_{\mathrm{i}}$ and $\mathrm{g}_{\mathrm{i}}$ are, respectively, ${ }^{30}$

$$
\begin{gathered}
\alpha_{\pi \mathrm{F}} \pi_{\mathrm{i}}+v\left(v\left(\pi_{\mathrm{i}}-\pi_{\mathrm{i}}^{\mathrm{e}}-\tau_{\mathrm{i}}\right)+\left(\mu+\omega_{\mathrm{i}}\right)-\tilde{\mathrm{x}}_{\mathrm{i}}\right)=\kappa \lambda_{\mathrm{i}}, \\
-v\left(v\left(\pi_{\mathrm{i}}-\pi_{\mathrm{i}}^{\mathrm{e}}-\tau_{\mathrm{i}}\right)+\left(\mu+\omega_{\mathrm{i}}\right)-\tilde{\mathrm{x}}_{\mathrm{i}}\right)=\lambda_{\mathrm{i}}, \\
\alpha_{\mathrm{gS}}\left(\mathrm{g}_{\mathrm{i}}-\tilde{\mathrm{g}}_{\mathrm{j}}\right)=-\lambda_{\mathrm{i}},
\end{gathered}
$$

Eliminate $\lambda_{\mathrm{i}}$ from the system (A.2)-(A.4) and add the government budget constraint to the system to obtain,

$$
\begin{gathered}
\alpha_{\pi \mathrm{F}} \pi_{\mathrm{i}}=-(\kappa+1) v\left(v\left(\pi_{\mathrm{i}}-\pi_{\mathrm{i}}{ }^{\mathrm{e}}-\tau_{\mathrm{i}}\right)+\left(\mu+\omega_{\mathrm{i}}\right)-\tilde{\mathrm{x}}_{\mathrm{i}}\right), \\
v\left(v\left(\pi_{\mathrm{i}}{ }^{\mathrm{e}}-\pi_{\mathrm{i}}+\tau_{\mathrm{i}}\right)+\tilde{\mathrm{x}}_{\mathrm{i}}-\left(\mu+\omega_{\mathrm{i}}\right)\right)=\alpha_{\mathrm{g} s}\left(\tilde{\mathrm{g}}_{\mathrm{i}}-\mathrm{g}_{\mathrm{i}}\right), \\
\mathrm{g}_{\mathrm{i}}+(1+\rho) \mathrm{d}_{\mathrm{i}}=\tau_{\mathrm{i}}+\kappa \pi_{\mathrm{i}}+\theta_{\mathrm{i}} .
\end{gathered}
$$

The solution of the system is derived in two steps. In the first step, we compute the deterministic components of the policy instruments (in other words, we compute the expected values of the policy instruments), while, in the second step, we compute the stochastic components of the policy instruments.

As for the first step, take expectations (denoted by superscript " $\mathrm{e}$ "; note that we assume rationality of expectations, so that subjective and model induced expectations are equal to each other) of both sides of the equations of the system (A.5)-(A.7):

$$
\begin{aligned}
& \alpha_{\pi \mathrm{F}} \pi_{\mathrm{i}}^{\mathrm{e}}=-(\kappa+1) v\left(-v \tau_{\mathrm{i}}^{\mathrm{e}}-\tilde{\mathrm{x}}_{\mathrm{i}}\right), \\
& v\left(v \tau_{\mathrm{i}}^{\mathrm{e}}+\tilde{\mathrm{x}}_{\mathrm{i}}\right)=\alpha_{\mathrm{gs}}\left(\tilde{\mathrm{g}}_{\mathrm{i}}-\mathrm{g}_{\mathrm{i}}^{\mathrm{e}}\right), \\
& \mathrm{g}_{\mathrm{i}}{ }^{\mathrm{e}}+(1+\rho) \mathrm{d}_{\mathrm{i}}=\tau_{\mathrm{i}}^{\mathrm{e}}+\kappa \pi_{\mathrm{i}}{ }^{\mathrm{e}}+\theta_{\mathrm{i}} \text {. }
\end{aligned}
$$

Rewrite $\left(\mathrm{A} .5^{\prime}\right)-\left(\mathrm{A} .7^{\prime}\right)$. The resulting system is:

$$
\begin{gathered}
\kappa \pi_{i}^{e}=\left(\kappa(\kappa+1) v^{2} / \alpha_{\pi F}\right)\left(\tau_{i}^{e}+\tilde{x}_{i} / v\right), \\
\tilde{g}_{i}-g_{i}{ }^{e}=\left(v^{2} / \alpha_{g S}\right)\left(\tau_{i}^{e}+\tilde{x}_{i} / v\right), \\
K_{i}=\left(\tau_{i}^{e}+\tilde{x}_{i} / v\right)+\left(\kappa \pi_{i}{ }^{e}\right)+\left(\tilde{g}_{i}-g_{i}{ }^{e}\right) .
\end{gathered}
$$

Substitute the right hand sides of (A.8) and (A.9) for $\left(\kappa \pi_{i}{ }^{e}\right)$ and $\left(\tilde{\mathrm{g}}_{\mathrm{i}}-\mathrm{g}_{\mathrm{i}}{ }^{\mathrm{e}}\right)$, respectively, into (A.10). The result can be solved for $\left(\tau_{i}^{e}+\tilde{x}_{i} / v\right)$ as a function of $K$. Using this result, the solutions for $(K \pi)$ and $(\stackrel{e}{g}-g)$ then

\footnotetext{
${ }^{30}$ The linear-quadratic structure of the model ensures that the optimal policy mix follows uniquely from the first-order conditions.
} 
follow from (A.8) and (A.9), respectively. Hence, the solution of the system (A.8) - (A.10) is given by:

$$
\begin{gathered}
\kappa \pi_{\mathrm{i}}^{\mathrm{e}}=\left[\left(\kappa(\kappa+1) / \alpha_{\pi \mathrm{F}}\right) / \mathrm{D}\right] \mathrm{K}_{\mathrm{i}}, \\
\tau_{\mathrm{i}}{ }^{\mathrm{e}}+\tilde{\mathrm{x}}_{\mathrm{i}} / v=\left[\left(1 / v^{2}\right) / \mathrm{D}\right] \mathrm{K}_{\mathrm{i}}, \\
\tilde{\mathrm{g}}_{\mathrm{i}}-\mathrm{g}_{\mathrm{i}}{ }^{\mathrm{e}}=\left[\left(1 / \alpha_{\mathrm{gS}}\right) / \mathrm{D}\right] \mathrm{K}_{\mathrm{i}},
\end{gathered}
$$

where $\mathrm{D} \equiv \kappa(\kappa+1) / \alpha_{\pi \mathrm{F}}+1 / v^{2}+1 / \alpha_{\mathrm{gS}}$, as defined in the main text.

Denote by superscript " $d$ " the deviation of a variable from its expected value (i.e. $x^{d} \equiv x-x^{e}$, where $x$ is an arbitrary variable). Subtract equations (A.5')-(A.7') from their counterparts of system (A.5)-(A.7) to yield:

$$
\begin{gathered}
\alpha_{\pi \mathrm{F}} \pi_{\mathrm{i}}^{\mathrm{d}}=(\kappa+1) v^{2}\left(-\pi_{\mathrm{i}}^{\mathrm{d}}+\tau_{\mathrm{i}}^{\mathrm{d}}-\left(\mu+\omega_{\mathrm{i}}\right) / v\right), \\
v^{2}\left(-\pi_{\mathrm{i}}^{\mathrm{d}}+\tau_{\mathrm{i}}^{\mathrm{d}}-\left(\mu+\omega_{\mathrm{i}}\right) / v\right)=-\alpha_{\mathrm{gS}} \mathrm{g}_{\mathrm{i}}^{\mathrm{d}}, \\
\mathrm{g}_{\mathrm{i}}^{\mathrm{d}}=\tau_{\mathrm{i}}^{\mathrm{d}}+\kappa \pi_{\mathrm{i}}^{\mathrm{d}} .
\end{gathered}
$$

Substitute (A.7") into (A.5"), to yield:

$$
v^{2}\left(-\pi_{i}^{d}+\tau_{i}^{d}-\left(\mu+\omega_{i}\right) / v\right)=-\alpha_{g S}\left(\tau_{i}^{d}+\kappa \pi_{i}^{d}\right)
$$

Combine (A.5") and (A.14) to yield,

$$
\left[\alpha_{\pi \mathrm{f}} /(\kappa+1)\right] \pi_{\mathrm{i}}^{\mathrm{d}}=-\alpha_{\mathrm{gS}}\left(\tau_{\mathrm{i}}^{\mathrm{d}}+\kappa \pi_{\mathrm{i}}^{\mathrm{d}}\right),
$$

which can be rewritten as,

$$
\tau_{\mathrm{i}}^{\mathrm{d}}=-\left[\left(\alpha_{\pi \mathrm{f}} / \alpha_{\mathrm{gg}}\right) /(\kappa+1)+\kappa\right] \pi_{\mathrm{i}}^{\mathrm{d}}
$$

Hence, the system to be solved consists of equations (A.5"), (A.7") and (A.16). Substitute the right hand side of (A.16) for $\tau_{i}^{d}$ into (A.5"). The resulting equation can be solved for $\pi_{i}^{d}$ to yield:

$$
\kappa \pi_{i}^{\mathrm{d}}=-\left[\left(\kappa(\kappa+1) / \alpha_{\pi \mathrm{F}}\right) / \mathrm{D}^{*}\right]\left[\left(\mu+\omega_{\mathrm{i}}\right) / v\right],
$$

where $\mathrm{D} \equiv(\kappa+1)^{2} / \alpha_{\pi \mathrm{F}}+1 / v^{2}+1 / \alpha_{\mathrm{gS}}$, as defined in the main text. Combine (A.17) with (A.16) to yield,

$$
\tau_{i}^{\mathrm{d}}=\left[\left(\kappa(\kappa+1) / \alpha_{\pi \mathrm{F}}+1 / \alpha_{\mathrm{gg}}\right) / \mathrm{D}^{*}\right]\left[\left(\mu+\omega_{\mathrm{i}}\right) / v\right]
$$

Next, combine (A.7"), (A.17) and (A.18) to yield,

$$
\mathrm{g}_{\mathrm{i}}^{\mathrm{d}}=\left[\left(1 / \alpha_{\mathrm{gS}}\right) / \mathrm{D}\right]\left[\left(\mu+\omega_{\mathrm{i}}\right) / v\right]
$$

The solution of $\kappa \pi_{i}$, as given in Table 1, is the sum of the right hand sides of (A.11) and (A.17). Similarly, the solution of $\tau_{i}+\tilde{x}_{i} / v$ is the sum of the right hand sides of (A.12) and (A.18), while $e_{i} \tilde{g}-g$ follows upon subtracting the right hand side of (A.19) from the right side of (A.13). Finally, we can write 


$$
\left(\tilde{\mathrm{x}}_{\mathrm{i}}-\mathrm{x}_{\mathrm{i}}\right) / v=-\pi_{\mathrm{i}}^{\mathrm{d}}+\left(\tau_{\mathrm{i}}+\tilde{\mathrm{x}}_{\mathrm{i}} / v\right)-\left(\mu+\omega_{\mathrm{i}}\right) / v .
$$

The solution of $\left(\tilde{\mathrm{x}}_{\mathrm{i}}-\mathrm{x}_{\mathrm{i}}\right) / v$ follows upon combining (A.17), the solution of $\left(\tau_{\mathrm{i}}+\tilde{\mathrm{x}}_{\mathrm{i}} / v\right)$ and (A.20).

Society's expected welfare loss follows upon substitution of the solutions for $\pi_{i}, \tilde{x}_{i}-x_{i}$ and $\tilde{g}-g$ into (2.3):

$$
\mathrm{E}\left(\mathrm{V}_{\mathrm{S}, \mathrm{i}}\right)=(1 / 2) \mathrm{E}\left(\frac{(\kappa+1)^{2} \alpha_{\pi \mathrm{S}}}{\alpha_{\pi \mathrm{F}}^{2}}+\frac{1}{v^{2}}+\frac{1}{\alpha_{\mathrm{gS}}}\right)\left(\left(\frac{1}{\mathrm{D}}\right) \tilde{\mathrm{K}}_{\mathrm{i}}+\left(\frac{1}{\mathrm{D}^{*}}\right)\left(\frac{\mu+\omega_{\mathrm{i}}}{v}\right)\right)^{2}
$$

Expression (3.1) follows immediately using the facts that $K_{i}$ is non-stochastic and that the shocks have zero expected value and are uncorrelated with each other.

\section{B: Derivation of the outcomes under decentralized discretion} (single-country case and monetary union)

The single-country case is obtained by setting $n=1$ in the outcomes for a monetary union (note that we have $K_{A}=K_{i}$ and $\omega_{A}=\omega_{i}$ if $\left.n=1\right)$.

Substitute (2.2), $\mathrm{i}=1, . ., \mathrm{n}$, into (4.1). Hence, the CCB selects $\pi$ to minimize

$$
1 / 2\left\{\alpha_{\pi M} \pi^{2}+\sum_{i=1}^{n}\left[\left(v\left(\pi-\pi^{e}-\tau_{i}\right)+\left(\mu+\omega_{i}\right)-\tilde{x}_{i}\right)^{2}+\alpha_{g M}\left(g_{i}-\tilde{g}_{i}\right)^{2}\right] / n\right\}
$$

The first-order condition for the inflation rate selected by the CCB is:

$$
\alpha_{\pi M} \pi+(1 / n) \sum_{i=1}^{n} v\left(v\left(\pi-\pi^{e}-\tau_{j}\right)+\left(\mu+\omega_{i}\right)-\tilde{x}_{i}\right)=0 .
$$

This can be solved to yield the CCB's reaction function (4.2):

$$
\pi=\left(\frac{v^{2}}{\alpha_{\pi M}+v^{2}}\right)\left(\pi^{\mathrm{e}}+\frac{1}{\mathrm{n}} \sum_{\mathrm{i}=1}^{\mathrm{n}}\left(\tau_{\mathrm{i}}+\left(\frac{\tilde{\mathrm{x}}_{\mathrm{i}}-\left(\mu+\omega_{\mathrm{i}}\right)}{v}\right)\right)\right) .
$$

The Lagrangian associated with government i's problem is:

$$
\mathfrak{f}_{\mathrm{F}, \mathrm{i}}=1 / 2\left[\alpha_{\pi \mathrm{F}} \pi^{2}+\left(v\left(\pi-\pi^{\mathrm{e}}-\tau_{\mathrm{i}}\right)+\left(\mu+\omega_{\mathrm{i}}\right)-\tilde{\mathrm{x}}_{\mathrm{i}}\right)^{2}+\alpha_{\mathrm{gS}}\left(\mathrm{g}_{\mathrm{i}} \tilde{\mathrm{g}}_{\mathrm{i}}\right)^{2}\right]+\lambda_{\mathrm{i}}\left[\mathrm{g}_{\mathrm{i}}+(1+\rho) \mathrm{d}_{\mathrm{i}}-\tau_{\mathrm{i}}-\kappa \pi-\theta_{\mathrm{i}}\right] .
$$

The first order conditions with respect to $\tau_{i}$ and $g_{i}$ are, respectively,

$$
\begin{gathered}
-v\left(v\left(\pi-\pi^{e}-\tau_{\mathrm{i}}\right)+\left(\mu+\omega_{\mathrm{i}}\right)-\tilde{\mathrm{x}}_{\mathrm{i}}\right)=\lambda_{\mathrm{i}}, \\
\alpha_{g \mathrm{gs}}\left(\mathrm{g}_{\mathrm{i}} \mathrm{g}_{\mathrm{i}}\right)=-\lambda_{\mathrm{i}},
\end{gathered}
$$

Eliminate $\lambda_{\mathrm{i}}$ from the system (B.5) and (B.6) to yield,

$$
\alpha_{g s}\left(\tilde{g}_{i}-g_{j}\right)=v\left(v\left(\pi^{e}-\pi+\tau_{i}\right)+\tilde{x}_{i}-\left(\mu+\omega_{i}\right)\right) .
$$


We employ again the two-step procedure. To solve for the deterministic components of the outcome, take expectations of (B.3), (B.7) and (2.5') to yield (after rewriting) the following system:

$$
\begin{gathered}
\kappa \pi^{\mathrm{e}}=\left(\kappa v^{2} / \alpha_{\pi \mathrm{M}}\right)(1 / \mathrm{n}) \sum_{\mathrm{i}=1}^{\mathrm{n}}\left(\tau_{\mathrm{i}}^{\mathrm{e}}+\tilde{\mathrm{x}}_{\mathrm{i}} / v\right), \\
\tilde{\mathrm{g}}_{\mathrm{i}}-\mathrm{g}_{\mathrm{i}}^{\mathrm{e}}=\left(v^{2} / \alpha_{\mathrm{g} S}\right)\left(\tau_{\mathrm{i}}^{\mathrm{e}}+\tilde{\mathrm{x}}_{\mathrm{i}} / v\right), \\
\mathrm{K}_{\mathrm{i}}=\left(\tau_{\mathrm{i}}^{\mathrm{e}}+\tilde{\mathrm{x}}_{\mathrm{j}} / v\right)+\left(\kappa \pi^{\mathrm{e}}\right)+\left(\tilde{\mathrm{g}}_{\mathrm{i}}-\mathrm{g}_{\mathrm{i}}^{\mathrm{e}}\right) .
\end{gathered}
$$

Combine (B.9) and (B.10) to yield:

$$
\tau_{\mathrm{i}}^{\mathrm{e}}+\tilde{\mathrm{x}}_{\mathrm{j}} / \nu=\left(1+v^{2} / \alpha_{\mathrm{gg}} \mathrm{S}^{-1}\left(\mathrm{~K}_{\mathrm{i}}-\kappa \pi^{\mathrm{e}}\right)\right.
$$

Substitute (B.11), i=1,..,n, into (B.8). The resulting equation can be solved to yield:

$$
\kappa \pi^{e}=\left[\left(\kappa / \alpha_{\pi M}\right) / N_{D}\right](1 / n) \sum_{i=1}^{n} K_{i}=\left[\left(\kappa / \alpha_{\pi M}\right) / N_{D}\right] K_{A},
$$

where $\mathrm{N}_{\mathrm{D}} \equiv \mathrm{K} / \alpha_{\pi \mathrm{M}}+1 / v^{2}+1 / \alpha_{\mathrm{gS}}$, as defined in the main text. Substitute (B.12) into (B.11) and work out further:

$$
\tau_{\mathrm{i}}^{\mathrm{e}}+\frac{\tilde{\mathrm{X}}_{\mathrm{i}}}{v}=\left(\frac{1 / v^{2}}{\mathrm{~N}_{\mathrm{D}}}\right) \tilde{\mathrm{K}}_{\mathrm{A}}+\left(\frac{1 / v^{2}}{1 / v^{2}+1 / \alpha_{\mathrm{gS}}}\right)\left(\tilde{\mathrm{K}}_{\mathrm{i}}-\tilde{\mathrm{K}}_{\mathrm{A}}\right) .
$$

Combine (B.9) and (B.13) to obtain:

$$
\tilde{\mathrm{g}}_{\mathrm{i}}-\mathrm{g}_{\mathrm{i}}^{\mathrm{e}}=\left(\frac{1 / \alpha_{\mathrm{gS}}}{\mathrm{N}_{\mathrm{D}}}\right) \tilde{\mathrm{K}}_{\mathrm{A}}+\left(\frac{1 / \alpha_{\mathrm{gS}}}{1 / v^{2}+1 / \alpha_{\mathrm{gS}}}\right)\left(\tilde{\mathrm{K}}_{\mathrm{i}}-\tilde{\mathrm{K}}_{\mathrm{A}}\right) .
$$

From (B.3), (B.7) and $\left(2.5^{\prime}\right)$ we obtain the system in terms of deviations from expected values:

$$
\begin{gathered}
\pi^{\mathrm{d}}=\left[v^{2} /\left(\alpha_{\pi \mathrm{M}}+v^{2}\right)\right](1 / \mathrm{n}) \sum_{\mathrm{i}=1}^{\mathrm{n}}\left[\tau_{\mathrm{i}}^{\mathrm{d}}-\left(\mu+\omega_{\mathrm{i}}\right) / v\right], \\
v^{2}\left[-\pi^{\mathrm{d}}+\tau_{\mathrm{i}}^{\mathrm{d}}-\left(\mu+\omega_{\mathrm{i}}\right) / v\right]=-\alpha_{\mathrm{g} g} \mathrm{~g}_{\mathrm{i}}^{\mathrm{d}}, \\
\mathrm{g}_{\mathrm{i}}^{\mathrm{d}}=\kappa \pi^{\mathrm{d}}+\tau_{\mathrm{i}}^{\mathrm{d}} .
\end{gathered}
$$

Substitute (B.17) into (B.16):

$$
v^{2}\left[-\pi^{\mathrm{d}}+\tau_{\mathrm{i}}^{\mathrm{d}}-\left(\mu+\omega_{\mathrm{i}}\right) / v\right]=-\alpha_{\mathrm{gS}}\left(\kappa \pi^{\mathrm{d}}+\tau_{\mathrm{i}}^{\mathrm{d}}\right),
$$

and solve for $\tau_{i}^{\mathrm{d}}$

$$
\tau_{i}^{\mathrm{d}}=\left(1 / v^{2}+1 / \alpha_{g \mathrm{~g}}\right)^{-1}\left[\left(1 / \alpha_{\mathrm{gS}}-\kappa / v^{2}\right) \pi^{\mathrm{d}}+\left(1 / \alpha_{\mathrm{gS}}\right)\left(\mu+\omega_{\mathrm{i}}\right) / v\right] .
$$

Substitute (B.19) into (B.15) to eliminate $\tau_{i}^{\mathrm{d}}$, and solve:

$$
\pi^{\mathrm{d}}=\left[-\left(1 / \alpha_{\pi \mathrm{M}}\right) / \mathrm{N}_{\mathrm{D}}{ }^{*}\right]\left[\left(\mu+\omega_{\mathrm{A}}\right) / v\right],
$$


where $\mathrm{N}_{\mathrm{D}}{ }^{*}=(\kappa+1) / \alpha_{\pi \mathrm{M}}+1 / v^{2}+1 / \alpha_{g \mathrm{~g}}$, as defined in the main text. Substitute (B.20) into (B.19) to eliminate $\pi$. Some algebra then gives,

$$
\tau_{\mathrm{i}}^{\mathrm{d}}=\left(\frac{\kappa / \alpha_{\pi \mathrm{M}}+1 / \alpha_{\mathrm{gS}}}{\mathrm{N}_{\mathrm{D}}^{*}}\right)\left(\frac{\mu+\omega_{\mathrm{A}}}{v}\right)+\left(\frac{1 / \alpha_{\mathrm{gS}}}{1 / v^{2}+1 / \alpha_{\mathrm{gS}}}\right)\left(\frac{\omega_{\mathrm{i}}-\omega_{\mathrm{A}}}{v}\right) .
$$

Substitute (B.20) and (B.21) into (B.17) to obtain:

$$
\mathrm{g}_{\mathrm{i}}^{\mathrm{d}}=\left(\frac{1 / \alpha_{\mathrm{gS}}}{\mathrm{N}_{\mathrm{D}}^{*}}\right)\left(\frac{\mu+\omega_{\mathrm{A}}}{v}\right)+\left(\frac{1 / \alpha_{\mathrm{gS}}}{1 / v^{2}+1 / \alpha_{\mathrm{gS}}}\right)\left(\frac{\omega_{\mathrm{i}}-\omega_{\mathrm{A}}}{v}\right) \text {. }
$$

Having solved the systems in terms of expectations and deviations from expectations, we can now combine the results to obtain the final outcomes. Combine (B.12) and (B.20) to obtain the solution of $\kappa \pi$ :

$$
\kappa \pi=\left(\frac{\kappa / \alpha_{\pi \mathrm{M}}}{\mathrm{N}_{\mathrm{D}}}\right) \tilde{\mathrm{K}}_{\mathrm{A}}-\left(\frac{\kappa / \alpha_{\pi \mathrm{M}}}{\mathrm{N}_{\mathrm{D}}^{*}}\right)\left(\frac{\mu+\omega_{\mathrm{A}}}{v}\right) .
$$

Combine (B.13) and (B.21) to obtain the outcome for $\tau_{\mathrm{i}}+\tilde{\mathrm{x}}_{\mathrm{i}} / v$ :

$$
\tau_{\mathrm{i}}+\frac{\tilde{\mathrm{X}}_{\mathrm{i}}}{v}=\left(\frac{1 / v^{2}}{\mathrm{~N}_{\mathrm{D}}}\right) \tilde{\mathrm{K}}_{\mathrm{A}}+\left(\frac{1 / v^{2}}{1 / v^{2}+1 / \alpha_{\mathrm{gS}}}\right)\left(\tilde{\mathrm{K}}_{\mathrm{i}}-\tilde{\mathrm{K}}_{\mathrm{A}}\right)+\left(\frac{\kappa / \alpha_{\pi \mathrm{M}}+1 / \alpha_{\mathrm{gS}}}{\mathrm{N}_{\mathrm{D}}^{*}}\right)\left(\frac{\mu+\omega_{\mathrm{A}}}{v}\right)+\left(\frac{1 / \alpha_{\mathrm{gS}}}{1 / v^{2}+1 / \alpha_{\mathrm{gS}}}\right)\left(\frac{\omega_{\mathrm{i}}-\omega_{\mathrm{A}}}{v}\right)(\mathrm{B} \cdot 24)
$$

Combine (B.14) and (B.22) to obtain the outcome for $\tilde{\mathrm{g}}_{i}-\mathrm{g}_{\mathrm{i}}$ :

$$
\tilde{\mathrm{g}}_{\mathrm{i}}-\mathrm{g}_{\mathrm{i}}=\left(\frac{1 / \alpha_{\mathrm{gS}}}{\mathrm{N}_{\mathrm{D}}}\right) \tilde{\mathrm{K}}_{\mathrm{A}}+\left(\frac{1 / \alpha_{\mathrm{gS}}}{1 / v^{2}+1 / \alpha_{\mathrm{gS}}}\right)\left(\tilde{\mathrm{K}}_{\mathrm{i}}-\tilde{\mathrm{K}}_{\mathrm{A}}\right)-\left(\frac{1 / \alpha_{\mathrm{gS}}}{\mathrm{N}_{\mathrm{D}}^{*}}\right)\left(\frac{\mu+\omega_{\mathrm{A}}}{v}\right)-\left(\frac{1 / \alpha_{\mathrm{gS}}}{1 / v^{2}+1 / \alpha_{\mathrm{gS}}}\right)\left(\frac{\omega_{\mathrm{i}}-\omega_{\mathrm{A}}}{v}\right) \text {. }
$$

As one can write

$$
\left(\tilde{\mathrm{x}}_{\mathrm{i}}-\mathrm{x}_{\mathrm{i}}\right) / v=-\pi^{\mathrm{d}}+\left(\tau_{\mathrm{i}}+\tilde{\mathrm{x}}_{\mathrm{i}} / v\right)-\left(\mu+\omega_{\mathrm{i}}\right) / v
$$

we can use (B.20) and (B.24) to obtain the outcome for $\left(\tilde{\mathrm{x}}_{\mathrm{i}}-\mathrm{x}_{\mathrm{i}}\right) / v$ :

$$
\frac{\tilde{\mathrm{x}}_{\mathrm{i}}-\mathrm{x}_{\mathrm{i}}}{v}=\left(\frac{1 / v^{2}}{\mathrm{~N}_{\mathrm{D}}}\right) \tilde{\mathrm{K}}_{\mathrm{A}}+\left(\frac{1 / v^{2}}{1 / v^{2}+1 / \alpha_{\mathrm{gS}}}\right)\left(\tilde{\mathrm{K}}_{\mathrm{i}}-\tilde{\mathrm{K}}_{\mathrm{A}}\right)-\left(\frac{1 / v^{2}}{\mathrm{~N}_{\mathrm{D}}^{*}}\right)\left(\frac{\mu+\omega_{\mathrm{A}}}{v}\right)-\left(\frac{1 / v^{2}}{1 / v^{2}+1 / \alpha_{\mathrm{gS}}}\right)\left(\frac{\omega_{\mathrm{i}}-\omega_{\mathrm{A}}}{v}\right) \text {. }
$$

Under the assumption that $\mathrm{K}_{\mathrm{i}}=\mathrm{K}, \forall \mathrm{i}$, we have that $\mathrm{E}\left(\mathrm{V}_{\mathrm{S}, \mathrm{i}}\right)=1 / 2 *$ Expected Value of

$$
\alpha_{\pi \mathrm{S}}\left(\left(\frac{1 / \alpha_{\pi \mathrm{M}}}{\mathrm{N}_{\mathrm{D}}}\right) \tilde{\mathrm{K}}-\left(\frac{1 / \alpha_{\pi \mathrm{M}}}{\mathrm{N}_{\mathrm{D}}^{*}}\right)\left(\frac{\mu+\omega_{\mathrm{A}}}{v}\right)\right)^{2}+
$$




$$
\begin{gathered}
\left(\left(\frac{1 / v}{\mathrm{~N}_{\mathrm{D}}}\right) \tilde{\mathrm{K}}-\left(\frac{1 / v}{\mathrm{~N}_{\mathrm{D}}^{*}}\right)\left(\frac{\mu+\omega_{\mathrm{A}}}{v}\right)-\left(\frac{1 / v}{1 / v^{2}+1 / \alpha_{\mathrm{gS}}}\right)\left(\frac{\omega_{\mathrm{i}}-\omega_{\mathrm{A}}}{v}\right)\right)^{2}+ \\
\alpha_{\mathrm{gS}}\left(\left(\frac{1 / \alpha_{\mathrm{gS}}}{\mathrm{N}_{\mathrm{D}}}\right) \tilde{\mathrm{K}}-\left(\frac{1 / \alpha_{\mathrm{gS}}}{\mathrm{N}_{\mathrm{D}}^{*}}\right)\left(\frac{\mu+\omega_{\mathrm{A}}}{v}\right)-\left(\frac{1 / \alpha_{\mathrm{gS}}}{1 / v^{2}+1 / \alpha_{\mathrm{gS}}}\right)\left(\frac{\omega_{\mathrm{i}}-\omega_{\mathrm{A}}}{v}\right)\right)^{2} .
\end{gathered}
$$

Assume that $\sigma_{\omega \mathrm{i}}{ }^{2}=\sigma_{\omega}{ }^{2}, \forall$ i. Hence, we have that

$$
\begin{gathered}
\mathrm{E}\left(\mathrm{V}_{\mathrm{S}, \mathrm{i}}\right)=\left(\frac{\alpha_{\pi \mathrm{S}} / \alpha_{\pi \mathrm{M}}^{2}+1 / v^{2}+1 / \alpha_{\mathrm{gS}}}{2 \mathrm{~N}_{\mathrm{D}}^{2}}\right) \tilde{\mathrm{K}}^{2}+ \\
\left(\frac{\alpha_{\pi \mathrm{S}} / \alpha_{\pi \mathrm{M}}^{2}+1 / v^{2}+1 / \alpha_{\mathrm{gS}}}{2\left(\mathrm{~N}_{\mathrm{D}}^{*}\right)^{2}}\right) \mathrm{E}\left(\frac{\mu+\omega_{\mathrm{A}}}{v}\right)^{2}+\left(\frac{1}{2\left(1 / v^{2}+1 / \alpha_{\mathrm{gS}}\right)}\right) \mathrm{E}\left(\frac{\omega_{\mathrm{i}}-\omega_{\mathrm{A}}}{v}\right)^{2},
\end{gathered}
$$

where we have made use of the fact that $\left(\mu+\omega_{A}\right) / v$ and $\left(\omega_{\mathrm{i}}-\omega_{\mathrm{A}}\right) / v$ are uncorrelated under the assumption that the idiosyncratic shocks have equal variance. From (B.29) it follows that,

$$
\begin{gathered}
\mathrm{E}\left(\mathrm{V}_{\mathrm{S}, \mathrm{i}}\right)=\left(\frac{\alpha_{\pi \mathrm{S}} / \alpha_{\pi \mathrm{M}}^{2}+1 / v^{2}+1 / \alpha_{\mathrm{gS}}}{2 \mathrm{~N}_{\mathrm{D}}^{2}}\right) \tilde{\mathrm{K}}^{2}+ \\
\left(\frac{\alpha_{\pi \mathrm{S}} / \alpha_{\pi \mathrm{M}}^{2}+1 / v^{2}+1 / \alpha_{\mathrm{gS}}}{2\left(\mathrm{~N}_{\mathrm{D}}^{*}\right)^{2}}\right)\left(\frac{\sigma_{\mu}^{2}+\sigma_{\mathrm{d}}^{2} / \mathrm{n}}{v^{2}}\right)+\left(\frac{1}{2\left(1 / v^{2}+1 / \alpha_{\mathrm{gS}}\right)}\right)\left(\frac{(\mathrm{n}-1) \sigma_{\omega}^{2} / \mathrm{n}}{v^{2}}\right),
\end{gathered}
$$

where we have made use of the assumption that the shocks are all uncorrelated with each other. ${ }^{31}$ Expression (B.30) can be rewritten as (4.3).

${ }^{31}$ Note that $\mathrm{E}\left(\mu+\sum_{i} \omega_{j} / \mathrm{n}\right)\left(\omega_{i}-\sum_{j} \omega_{j} / \mathrm{n}\right)=\mathrm{E}\left(\omega_{1} \sum_{j} \omega_{j} / \mathrm{n}-\sum_{i} \omega^{2} / \mathrm{n}\right)=(1 / \mathrm{n}) \mathrm{E}\left(\phi^{2}\right)-(1 / \mathrm{n}) \sum \mathrm{E}\left(\phi^{2}\right)=0$, where we have used the assumption that the common shock is uncorrelated with the idiosyncratic shocks and repeatedly used the assumption that the idiosyncratic shocks are uncorrelated with each other. 